\title{
Performance-based analysis of large steel truss roof structure in fire
}

\author{
Limin $\mathrm{Lu}^{1,2}$, Guanglin Yuan ${ }^{1}$, Zhaohui Huang ${ }^{3,}$, Qianjin Shu ${ }^{2}$, Qing $\mathrm{Li}^{2}$ \\ ${ }^{1}$ State Key Laboratory for Geomechanics and Deep Underground Engineering, China University of \\ Mining and Technology, Xuzhou, 221116, China \\ 2 Department of Architecture and Civil Engineering, China University of Mining \& Technology, \\ Xuzhou, Jiangsu 221116, China \\ ${ }^{3}$ Department of Mechanical, Aerospace and Civil Engineering, Brunel University, Uxbridge, \\ Middlesex UB8 3PH, UK
}

\begin{abstract}
Due to the fast developments of large-space multi-functional architectures, large-span steel structures have been widely used in recent years. Therefore, the fire-resistance design of this kind of structures has attracted more attentions. Since traditional ISO834 standard fire curve is not suitable for large space structures, performance-based fire resistance design method is required. This paper presents the comprehensive case studies on the fire performance of a large space exhibition centre in Shanxi province, China under real fire scenarios including heating and cooling phases. The non-uniform fire temperature fields of the large space exhibition centre for the designed fire scenarios have been generated by using Fire Dynamic Simulator (FDS). A finite element (FE) model has been developed using FE software ANSYS for modelling the structural behaviour of the exhibition centre under different fire scenarios. Based on the results generated in this research some recommendations for the fire resistance design of large space steel truss structures have been proposed.
\end{abstract}

Keywords: Performance-based; fire-resistance; large steel truss structure; fire scenario; local cooling; structural behaviour.

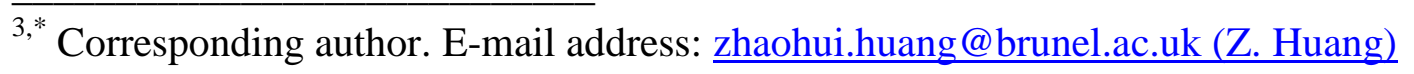




\section{Highlights:}

Conduct a comprehensive case study on the fire behaviour of an exhibition centre.

Generate the temperature fields of the fires and structural members in the building.

Simulate the structural behaviours of the exhibition centre under different fires.

$>$ Propose some design recommendations for large space structures against fire. 


\section{Introduction}

With the developments of technology and economy, a variety of complex and large-scale buildings are getting more and popular. Larger span steel structures are adopted to satisfy the requirements of modern architectural designs. Thus, traditional - prescriptive- design method cannot meet the actual needs of constructions, especially for the fire resistance design of large space buildings, such as exhibition halls, stadiums, theatres, tall sharing spaces, and so on. Previous researches [1, 2] indicate that prescriptive methods are sometimes too conservative or not safe enough for the structural fire engineering design of large-scale buildings. Therefore, at present performance-based design method is recommended for the fire resistance design of this kind of buildings, which has been proved by many researches and practical experience [3]. In the performance-based fire resistance design, the fire behaviour of a building should be analysed based on the space and structural character of the building and real fire scenarios that building may undergo [4]. The temperature field of the real fire scenarios in a large-scale building should be analysed and then coupled into the structural performance study of that building [5].

Compared to normal office buildings, a fire within a large space structure happens in a limited area within the building and the hot air only influences that part of the building's space. The temperature field within a large space structure is much more different than that a normal office building. Therefore, the standard temperature-time curve is not suitable to represent the temperature distribution within large space structures. Du and Li [6], Xue et al. [7] and Fan et al. [8] have developed the numerical models for predicting temperature fields of the fires in large space buildings based on the fire development using Fire Dynamics Simulator (FDS) [9]. The models mentioned above can more accurately simulate the temperature distribution of the fires within large space structures. However, these models do not consider the cooling process of a fire.

Currently, the researches on the structural response of large space steel truss structures under real fire scenarios are still limited, especially considering whole heating-cooling process. Liu et al. [10] carried out the full scale fire tests on two steel truss structures. The research indicated that the damage of planar circular steel tube truss was mainly caused by the local yielding of the web tubes. With the increase of load ratio, the fire resistance of a planar circular steel tube truss decreases 
gradually. Moreover, Zhao and Shen [11] have developed a numerical model by using finite element software ABAQUS to predict the fire resistance of the planer steel tube truss structures and the results showed that the fire-resistance of the structures decreased with increasing temperature and load ratio.

Li et al. [12, 13] have developed a finite element model by using ABAQUS for analysing the non-linear fire performance of steel frames. The model took into account the material and geometric nonlinearities, and non-uniform temperature field within steel frames. Yin and Wang [14, 15] have done a series of researches on the fire resistance of steel beams. However, the researches mentioned above didn't consider the characteristic of a fire in large space structures. From the authors' knowledge, the researches on the fire performance of large space steel tube truss structures under real fire scenarios are still very limited and further researches are needed. Therefore, the main objectives of this research are:

- Conduct a comprehensive case study by using performance-based approach on the fire resistance of a large space exhibition centre in Shanxi province, China under real fire scenarios including heating and cooling phases;

- Generate the non-uniform fire temperature fields of a large space exhibition centre for the designed fire scenarios by using FDS finite element package [9];

- Calculate the temperatures of the structural members within the large-space steel truss structure based on the local fire temperature fields. Then a finite element (FE) model is developed using FE software ANSYS. The non-uniform temperatures of different structural members within the large space exhibition centre are inputted into the FE model to simulate the structural behaviour of the exhibition centre under different fire scenarios;

- Give a comprehensive demonstration for practical engineers to show how fire resistance of a large-space steel truss structure can be assessed based on performance-based fire design approach;

- Propose some recommendations for the fire resistance design of large space steel truss structures. 


\section{Fire scenarios design for large space structures}

\subsection{Project overview}

Fig. 1 shows a 52,000 $\mathrm{m}^{2}$ exhibition centre located in Taiyuan, Shanxi Province, China. This exhibition centre was used in this paper for the comprehensive case study on the thermal and structural behaviours of a large space exhibition centre. The exhibition centre is a typical large space frame structure with a large-span roof constructed with steel trusses. As shown in Fig 2 the building is composed by two circles, with an out circle of $229 \mathrm{~m}$ in diameter and an inner circle of $50 \mathrm{~m}$ in diameter. The total area of the first layer is $46600 \mathrm{~m}^{2}$ and was designed to be one fireproofing zone. As an exhibition centre, it consists of six exhibition halls (the area of $1 \#$ and 6\# is $6518 \mathrm{~m}^{2}$ and that of $2 \#$ to $5 \#$ is $\left.4675 \mathrm{~m}^{2}\right)$, a main entrance hall $\left(3693 \mathrm{~m}^{2}\right)$ and a circle gallery (3670 $\mathrm{m}^{2}$ ) in the inner centre. The whole roof of the building was constructed by spatial intersection steel trusses into an arc structure. The lowest position on the bottom chord of the steel truss structure is $12 \mathrm{~m}$ and the highest point on the steel truss structure is $26 \mathrm{~m}$.

It can be seen that the area of the fireproofing zone is much larger than the requirements specified by the Chinese code for fire protection design of buildings (GB 50016-2014) [16], which is 10000 $\mathrm{m}^{2}$ for maximum. The maximum evacuation distance of $114.5 \mathrm{~m}$, which is the radius of the out circle of the building, is also larger than the value specified by the code. Therefore, it is needed to adopt performance-based approach for the fire-resistance design of such large buildings.

According to the Chinese fire safety design codes $[16,17]$, the performance-based fire resistance designed approach for this lager space exhibition centre is needed. The detail procedures are:

(1) To determinate typical upper-bound and lower-bound design fire scenarios and corresponded fire temperature distribution histories within a structure;

(2) Calculate the temperature fields for all structural members inside the structure for the required fire exposing time;

(3) Compute the loading conditions of the structure, which take into account the load combination effect according to the Chinese codes; 
(4) Conduct structural modelling to calculate the deflections, forces, stresses for all structural members under each fire condition;

(5) Check the fire resistance of the structure based on the deflection and ultimate load bearing capacities of the structural members and the stability of the whole structure;

(6) Determinate structural members' sizes or apply the fire protection to certain structural members until the structure fulfils the fire resistance requirements.

\subsection{Design of fire scenarios}

Fire scenario design is one of the most critical processes during performance-based fire resistance design. It should be designed based on the most unfavourable principles, including: the design of fire load, the location and area of fire sources, the model of fire development and the maximum heat release rate $(\mathrm{HRR})$ of a fire.

\subsubsection{Fire sources}

As an exhibition centre, the main fire source should be the exhibits. The magnitude of fire load of combustible materials differs for various location and quantities. According to Fire Engineering Design Guide [5], the fire load of general auto exhibition is $200 \mathrm{MJ} / \mathrm{m}^{2}$, furniture exhibition is 500 $\mathrm{MJ} / \mathrm{m}^{2}$, machinery exhibition is $80 \mathrm{MJ} / \mathrm{m}^{2}$ and art exhibition is $200 \mathrm{MJ} / \mathrm{m}^{2}$. Under an overall consideration, the furniture exhibition was adopted in this study.

Since the top of the circle gallery of the exhibition centre is an open space, if the fires occur in the areas near the centre, the hot air can be ventilated to the outside of the building directly, so fire sources occurring in or near the circle gallery were not investigated in this paper. From the floor layout shown in Fig. 2, it can be seen that the fires occurring near the entrance hall will directly affect the occupant's evacuation and are more dangerous. Moreover, the height of exhibition platform within the exhibition centre is $3 \mathrm{~m}$ to $4 \mathrm{~m}$, so in this study the height of the fire location was set to be $4 \mathrm{~m}$. Based on above discussions, two fire source locations were assumed in the exhibition centre, as shown in Fig. 3:

(1) Fire source A: The fire occurred on the exhibition platform near the out wall of 5\# Hall. 
(2) Fire source B : The fire occurred on the exhibition platform in the centre of $6 \#$ Hall.

\subsubsection{Fire development model and maximum heat release rate}

The fire development within a large space is very complex problem, normally in the performance-based fire-resistance design some conservative assumptions are made for the fire spread. Therefore, in this research the fire development curve was assumed to be constant after the heat release rate reached to the maximum value as shown in Fig. 4 [7], ignoring the decay period of the fire source.

The fire development model can also be expressed as the relationship between heat release rate and fire lasting time. At present, the most popular model used is:

$$
Q=\alpha t^{2}
$$

where, $Q$ is heat release rate $(\mathrm{kW}) ; \alpha$ is fire growth rate $\left(\mathrm{kW} / \mathrm{s}^{2}\right) ; t$ is the fire lasting time $(\mathrm{s})$.

US Standard for Smoke and Heat Venting [18] defines four categories of fires according to fire growth rate $\alpha$, which are: slow fire, medium fire, rapid fire and ultra-fast fire. As mentioned before, the design of fire in this study was based on the most unfavourable principles. Hence, the fast fire was considered with $\alpha=0.04689 \mathrm{~kW} / \mathrm{s}^{2}$. As mentioned in Section 2.2.1, for an exhibition centre, the main fire source should be the exhibits. Hence, it is reasonably assumed that the fire source of this project was furniture exhibits. According to Chinese code for the fire protection design of buildings [16], the heat release rate (HRR) of a unit area for the furniture exhibits is $100 \mathrm{~kW} / \mathrm{m}^{2}$. This value was used in this study. Also, in accordance with the requirements of the exhibition centre to store or display different items, two fire source areas were considered. The first fire source area was based on the area of one exhibition platform, which was $9 \times 9 \mathrm{~m}^{2}$. The second fire source area was based on the area of two exhibition platform, which was $18 \times 18 \mathrm{~m}^{2}$. In reality the case with large area is not always happened, which represents more extreme fire scenario. However, the case with small area is frequently happened under normal condition. In the reality the combustible fuel near the fire source can be ignited due to the radiation of the flames and fire can spread within the exhibition center. However, for simplicity this situation was not considered in this study. 


\subsubsection{Fire scenarios}

According to the most unfavourable principle and taking the dangerous factors of a real fire disaster into consideration, four fire scenarios were designed for the exhibition centre, as listed in Table 1. It was assumed that the fire fighting system is out of work in all four fire scenarios.

\subsection{Modelling of fire temperature fields within the exhibition centre}

Due to the lager space of the exhibition centre it is obvious that zone modelling approach is not suitable for modelling the fire. Hence, in this study the fire development within this large space exhibition centre was modelled by using Fire Dynamics Simulator (FDS) FE package [9]. FDS has been used by many researchers in the world for fire dynamics simulation and has been validated intensively with test data [19]. FDS can analyse the gas diffusion and heat conduction in the combustion process, including combustion, thermal radiation and pyrolysis models. Therefore, FDS package was adopted in this project to simulate the real fire scenarios of the exhibition centre, in order to study the non-uniform fire temperature field within the large-space steel structure. Some bench mark tests were done to assess the accuracy or reliability of numerical results generated from the program. The predicted non-uniform fire temperature field by FDS was used to predict the temperatures of the steel structural members for the structural analysis of the exhibition centre.

In the simulation of FDS, the grid size is an important modelling parameter as it determines the accuracy of modelling results. The density, velocity, temperature and pressure of each grid are all calculated for every time step and the parameters of each grid are also time-dependent. Therefore, good mesh size of the model in FDS is the key factor which affects the accuracy of the results. In theory, the finer the mesh, the higher the accuracy of the results. However, since for a large-space structure, many grids, even up to millions of grids, are needed, the simulation will have considerable demand on computational power and time. Therefore, structural scale, accuracy and time of the simulation should all be considered for selecting the mesh size. Based on the previous

research [8, 19], in this study a mesh size of $1 \times 1 \times 0.5 \mathrm{~m}^{3}$ has been adopted to simulate the fire development within the exhibition centre. From the results (see Figs 7 and 9) it is evident that the temperature within a mesh volume is relatively uniform. The combustion model of fire in FDS is 
the key for the simulation of fire scenarios. In this study, modeling tool PYROSIM, developed by Thunderhead Engineering Company, is used to create the FDS model.

In this study, four different fire scenarios were simulated to predict smoke and gas distribution and temperature field within the exhibition centre. Fig. 5 shows the fire simulation model established using FDS for the exhibition centre. The large space structure was meshed into $1 \times 1 \times 0.5 \mathrm{~m}^{3}$ small volume elements, with 3920 measuring points which were related to 3920 nodes below the bottom chord of the structure. The fire duration was assumed to be 1.5 hour $(5400 \mathrm{~s})$, and the time step was $10 \mathrm{~s}$. The temperature-time curves of the measuring points were recorded and were used to calculate the temperature field of the steel members.

\subsubsection{Fire scenarios with fire source location A}

Fig. 6 shows the predicted smoke and gas distributions of Fire Scenarios 1 and 3 (see Table 1). The predicted temperature distributions of Fire Scenarios 1 and 3 at height of $12 \mathrm{~m}$ are shown in Fig. 7. From Figs 6 and 7, it can be concluded that:

(1) For the fire location near the outer wall (fire source location A), the smoke risen in an axial symmetric plume form. When the smoke reached the ceiling, the part of the smoke spread outwards and transferred into the central courtyard then finally was ventilated to the outside of the building. Hence, after $600 \mathrm{~s}$ of the fire, only the gas near the fire source location had obvious temperature increasing.

(2) The distribution of the temperature field was non-uniform in the areas closed to the fire source location with the highest gas temperature right above the fire source location and the gas temperature was decreased with the increasing distance from the fire source location. Due to the influence of the central courtyard, the gas temperature on the left-hand side of the building was higher than that of right-hand side for the same distance away from the fire source location. After $5400 s$ of the fire, the highest temperatures for Fire Scenarios 1 and 3 were about $400{ }^{\circ} \mathrm{C}$ and $300{ }^{\circ} \mathrm{C}$, respectively.

(3) After $600 s$ of the fire, the smoke reached the furthest place of the hall for Fire Scenario 1, however, for Fire Scenario 3 the smoke only reached about the half way of the hall with a 
relatively small expanded area and lower height. This demonstrated that the fire source area is a critical factor to influence the spreading of a fire. Larger fire source area leads to a higher gas temperature near the fire source location and a larger fire hazarded area.

(4) After 5400s of the fire, the hot gas and smoke expended the entire space of the hall. For Fire Scenario 1 the gas temperatures were above $60{ }^{\circ} \mathrm{C}$ within the area of $1000 \mathrm{~m}^{2}$. However, For Fire Scenario 3 only the temperature of the area of $500 \mathrm{~m}^{2}$ closed to the fire source location had notable increase. Therefore, the fire source area has a significant impact on the temperature field of a fire, the large fire source area leads to a sever fire.

\subsubsection{Fire scenarios with fire source location $B$}

The predicted smoke and gas distributions of Fire Scenarios 2 and 4 (see Table 1) are presented in Fig. 8. The predicted temperature distributions of Fire Scenarios 2 and 4 at height of $12 \mathrm{~m}$ of the structure are shown in Fig. 9. From Figs 8 and 9, it can be seen that the patterns of the smoke distribution and gas temperature field of Fire Scenarios 2 and 4 were similar with Fire Scenarios 1 and 3, respectively. The highest gas temperatures above the fire source location were $360{ }^{\circ} \mathrm{C}$ and $260{ }^{\circ} \mathrm{C}$ for Fire Scenario 2 and Fire Scenario 4, respectively.

It is clear that the highest temperatures of the fires with the same fire source area at the fire source location A were higher compared to the fire at the fire source location B. This is because the fire source location B is closed to the central courtyard of the hall and the net height of the space is larger. Another factor is that the smoke and hot gas are more easily to be ventilated to the outside of the hall through the opening of the courtyard. However, the results show that the influence of fire source area is more significant compared to the fire source location. It is evident from this research that the temperature fields of the fire scenarios presented here are very non-uniform and the ISO834 standard fire curve is not suitable for the fire resistance design of the structures with large space.

\subsection{Temperature calculations for steel structural members}

The main objective of this research is to assess the fire resistance of large steel roof structure without any passive fire protection for an exhibition hall using performance-based approach. Hence, the temperatures of all steel truss members were calculated based on the local fire temperature field 
for different fire scenarios. And then, the temperatures of all structural members were imputed into the structure model build in ANSYS (see Fig. 10) for the structural simulation.

\subsubsection{The Simplified calculation method}

In this study, the non-uniform temperature field of the steel members for the exhibition centre was calculated using the simplified calculation method proposed in the Chinese Code: "Technical specification for fire protection of steel structure of buildings" [17]. The ambient temperature was assumed to be $20^{\circ} \mathrm{C}$, and then the temperature of the steel truss member can be calculated as:

$$
T_{\mathrm{s}}(t+\Delta t)=\frac{B}{\rho_{s} c_{s}}\left[T_{g}(t)-T_{s}(t)\right] \cdot \Delta t+T_{s}(t)
$$

where $\Delta t$ is the time step, which is $30 \mathrm{~s}$ in this study (s);

$T_{s}$ is the temperature of the steel truss member $\left({ }^{\circ} \mathrm{C}\right)$;

$T_{g}$ is the local air temperature around the steel truss member $\left({ }^{\circ} \mathrm{C}\right)$;

$B$ is the heat transfer coefficient of unit length steel member $\left(\mathrm{W} /\left(\mathrm{m}^{3} \cdot{ }^{\circ} \mathrm{C}\right)\right)$;

$c_{s}$ is the specific heat capacity of steel $\left(600 \mathrm{~J} /\left(\mathrm{kg} \cdot{ }^{\circ} \mathrm{C}\right)\right)$;

$\rho_{s}$ is the density of the steel $\left(7850 \mathrm{~kg} / \mathrm{m}^{3}\right)$.

The heat transfer coefficient of unit length steel member $B$ without fire protection can be calculated as:

$$
\begin{aligned}
& B=\left(\alpha_{c}+\alpha_{r}\right) \frac{F}{V} \\
& \alpha_{r}=\varepsilon_{r} \sigma \frac{\left(T_{g}+273\right)^{4}-\left(T_{b}+273\right)^{4}}{T_{g}-T_{s}}
\end{aligned}
$$

Where: $F$ is the fire exposing area of the unit length of steel member $\left(\mathrm{m}^{2} / \mathrm{m}\right)$;

$V$ is the fire exposing volume of the unit length of steel member $\left(\mathrm{m}^{3} / \mathrm{m}\right)$;

$\alpha_{c}$ is the heat transfer coefficient, $\alpha_{c}=25 \mathrm{~W} /\left(\mathrm{m}^{2}{ }^{\circ} \mathrm{C}\right)$;

$\varepsilon_{r} \quad$ is the overall heat radiance, $\varepsilon_{r}=0.5$; 
$\sigma$ is Stefan-Boltzmann factor, $\sigma=5.67 \times 10^{-8}\left[\mathrm{~W} /\left(\mathrm{m}^{2} \cdot \mathrm{K}^{4}\right)\right]$.

It is well known that MATLAB is an advanced technology computing language and interactive environment for algorithm development, data visualization, data analysis and numerical calculation. Users can write in the command window to synchronize the input statement with the execution command and can also write a complex application ( $\mathrm{M}$ file) and then run the commands together. Hence, the simplified method presented above has been written into an M-file in MATLAB program to calculate the non-uniform temperature field of the steel truss members. The local air temperatures around the steel truss members ( $\mathrm{Tg}$ ) were determined from the temperature-time curves predicted by FDS modelling for the different design fire scenarios.

\subsubsection{Temperature field of the structures under different fire scenarios}

As mentioned in Section 2.4.1, the temperatures of all truss members of the structure were calculated using Eq. (2) based on the predicted non-uniform fire temperature field for different fire scenarios. The temperature data of all truss members were inputted into structural analysis model to simulate the structural behaviour of the exhibition centre under different fire conditions. Fig. 11 shows the calculated temperature distributions of the structural members for different fire scenarios.

The predicted temperatures of the truss members at different positions related to the fire source for four designed fire scenarios are presented in Fig. 12. As shown in the figure, Position E1 is just right above the fire source; Positions E2 and E4 are both on the left-hand side of E1 and $1 \mathrm{~m}$ and 2 $\mathrm{m}$ away from E1, respectively. Positions E3 and E5 are both on the right-hand side of E1 and $1 \mathrm{~m}$ and $2 \mathrm{~m}$ away from E1, respectively.

It can be seen from the figure that the maximum temperatures of the steel truss members were lower than $350{ }^{\circ} \mathrm{C}$ for the different fire scenarios. The temperatures of the steel truss members were gradually reduced away from the fire sources. The fire source area and location have a considerable influence on the temperatures of the steel truss members. Hence, in order to do the performance-based fire resistance, the temperatures of all steel truss members need to be evaluated respectively.

\section{Development of finite element structural model for the exhibition centre}


A general-purpose finite element software, ANSYS has become the mainstream simulation analysis software for civil engineering and construction all over the world. It has been widely used for the analysis of steel and reinforced concrete buildings, stadiums, bridges and underground structures under external loading conditions. More extensive validations of ANSYS for modelling thermal and structural behaviours of steel, concrete and composite structures under fire conditions have been conducted in previous researches [20, 21]. For steel structures, especially the large-space steel structures developed in recent years, ANSYS has obvious advantages compared with other finite element software, that is: powerful modelling capability, strong solving and nonlinear analysis abilities, good mesh ability, and optimization, advanced single and multi-field coupling analysis ability, multiple interfaces, strong processing and secondary development abilities. ANSYS provides users with parameterized design language APDL (ANSYS Parameter Design Language) to operate the finite analysis automatically. The APDL language can be used for the parametric modelling, parametric loading and solving, parametric results showing after treatment and also for the optimization of design and analysis. Therefore, in this research ANSYS was used for the structural modelling of the exhibition centre under different fire conditions. Some bench mark tests were carried to validate the accuracy of numerical results predicted from the software. Also the mesh sensitivity was done for selecting reasonable mesh size for larger scale modelling.

\subsection{Structural model}

The FE model for this large space steel truss structure was built in ANSYS as shown in Fig. 10. In this ANSYS structural model both geometric and material nonlinearity were considered. The total element number of the model was 28448 with 8064 nodes in which 4144 nodes on the top chord and 3920 nodes on the bottom chord of the structure. All the steel trusses members were constructed using Q345 steel tubes. Table 2 lists the cross-section sizes of the steel tube elements used for a typical truss girder (as shown in Fig. 10 (c)) and the main circular elements on the top and bottom chords of the roof structure. In Table 2: elements 1-36 are the top chord member of the truss girder arranged from inside circle to outside circle; elements 8513-8546 are the bottom chord member of the truss girder arranged from inside circle to outside circle; elements 16689-16723 are vertical web truss members of the truss girder arranged from inside circle to outside circle; elements 
20609-20643 are diagonal web truss members of the truss girder arranged from inside circle to outside circle (see Fig. 10(c)). Elements 8065, 8177, 8289, 8401 are the main circular members of the top chord of the roof structure arranged from inside circle to outside circle; elements 16129 , $16241,16353,16465,16577$ are the main circular members of the bottom chord of the roof structure arranged from inside circle to outside circle.

The steel material properties are:

The thermal conductivity $\lambda_{\mathrm{s}}=45 \mathrm{~W} /(\mathrm{m} \mathrm{K})$;

The specific heat $\mathrm{c}_{\mathrm{s}}=600 \mathrm{~J} /(\mathrm{kg} \cdot \mathrm{K})$;

The thermal expansion factor $\alpha_{\mathrm{s}}=1.4 \times 10^{-5}$;

The density $\rho_{\mathrm{s}}=7850 \mathrm{Kg} / \mathrm{m}^{3}$;

The Poisson ratio $v_{\mathrm{s}}=0.3$;

The yielding strength at ambient temperature $f_{\mathrm{y}, 20}=356 \mathrm{MPa}$.

The constitutive material model of Q345 steel tubes at elevated temperatures developed by Yuan et al. [22] was adopted in this study.

All the joints of the steel tube trusses are tubular joints. The top and bottom chord trusses are continuous through members and the web trusses penetrated into chord trusses. According to the "Design code of steel structures" (GB 50017-2003 [23]), the connections of the trusses may be considered as hinges if the following requirements are fulfilled:

(1) The geometric parameters are in the required scope of the correspond connections;

(2) The length/ height ratio of the chord trusses is larger than 12 and that of the web trusses is smaller than 24 .

The requirement (1) mainly limit the radius ratio between the chord trusses and web trusses, the angles between the chord trusses and the web trusses, the diagonal angle of the joints, the lap ratios and so on. Although the requirement (1) is fulfilled, if the length/ height ratio of the chord trusses is less than 12 or that of the web trusses is bigger than 24 , the joints may be regarded as a rigid joint. 
In this study, most of the length/ radius ratios of the chord trusses were larger than 12 and most of these for web trusses were larger than 24. Hence, in the FE model, the steel structural members on the top and bottom chords of the structure were represented as beam elements and connected rigidly each other. Other steel truss members connected to truss girders were modelled as an assembly of truss elements connected by semi-rigid connections, with the property between the rigid connection and the hinge which takes the nonlinear relationship of bending moment and rotational displacement into consideration. According to EC3 [24], the connection with the rotational stiffness between 0.5 25 times of its linear stiffness should be considered as semi-rigid connection. The web truss members were represented as truss elements and the connections between the web truss members and the members on the top and bottom chords were pinned. The supports of the structure are shown in Fig. 13. It is reasonable assumed that the supports at the bases of the columns can rotate in the radius direction and other degrees of freedom were fixed. In the ANSYS structural model all columns were included in the model.

\subsection{Loading conditions}

During the modelling process of the large space steel roof structure, the loads applied on the effective area of the nodes within the structure were calculated based on the static load equivalent principle, which is so called equivalent nodal load. For ANSYS, it is difficult to obtain the equivalent nodal load effectively and accurately with the normal comments provided by the graphical user interface (GUI) for the following reasons:

(1) Firstly, in real large-scale structures, the nodes of polygons are not in the same surface, they are spaced polygons. For the spaced polygons it is difficult to compute the equivalent nodal loads.

(2) Secondly, a large space steel roof structure contains a large number of members and nodes, the work of calculating the uniform load of each grid one by one is too time consuming and difficult to perform.

(3) Thirdly, the "SF" command supplied by ANSYS applies the surface load on a group of nodes which requires that the load should be perpendicular to the surface. If the load is not perpendicular to the surface like the suspension load of the curved steel roof, the "SF" command cannot be used. 
In order to overcome these limitations, a time effective and precise approach for calculating the equivalent nodal load was proposed in this study. The proposed method was conducted by writing comments using APDL language, applying all the dead load, live load and wind load on the roof structure and then calculating the equivalent nodal loads.

The main objective of this paper is to investigate the influence of various fire scenarios (fire source locations and fire areas) on the structural performance of large space steel tube structures. For the large space steel roof structure the main live loads are snow and wind loads. For the snow load, it's not the common situation that when the larger snow loads are applied to the structure when a fire happens in the structure. Hence, according to the Chinese code [16] the snow load can be ignored for the fire-resistance design of structure under fire limit state. Also the wind load can be neglected when the effect of frequency of live load is bigger than the combined effect of wind load and permanent live load. Therefore, the main loads were assumed to be static loads, so the live loads, such as wind and snow loads, were not considered in this research. Hence, only the permanent loads were applied to the structure, including the weight of structural members, roofing materials, equipment, pipes and lightings.

The self-weight of the structural member was calculated automatically according to geometric dimensions of the member by the software. The weight of the roofing materials (glass curtain roof of $5 \mathrm{~mm}$ lead wire glass including frame weight) was $300 \mathrm{~N} / \mathrm{m}^{2}$. The weight of the equipment, pipes and lightings (taking the standard value) was $1000 \mathrm{~N} / \mathrm{m}^{2}$. The weight of the roofing materials were applied on the top nodes and that of the equipment were applied on the bottom nodes, and then the equivalent nodal loads can be calculated by the proposed method described above.

\section{Structural response of the exhibition centre under different fire conditions}

\subsection{The deformation of the structure}

The results indicated that the vertical displacements of the structural members changed with their temperatures. The nodes within the span part of the structure were moved upwards while the nodes on the cantilever part were moved downward (see Fig. 13(a) for the cantilever part and span part of the roof structure). Fig.14 shows the vertical nodal displacement contours in 
the top chord of the steel truss structure for four different fire scenarios at time of $5400 s$, in which the downward displacement is negative and upward displacement is positive.

It can be seen from the figure that for Fire Scenarios 1 and 2, the absolute maximum negative displacement (downward) appeared on the cantilever part of the top chord in the area closed to the fire source. The absolute maximum positive displacement (upward) formed at a node in the area between the fire source location and the out-circle supports of the structure, in which the temperature of the member at that node position was lower than the member right above the fire source location. This is because that the node at the member with highest temperature had largest negative displacement at ambient temperature which counteracted the part of the positive displacement generated in the fires. For Fire Scenarios 3 and 4, the upward nodal displacements caused in the fires were not big enough to counteract the initial negative nodal displacements at ambient temperature, so nearly all nodal displacements were negative displacements.

Fig. 15 shows the vertical nodal displacement contours in the bottom chord of the steel truss structure for four fire scenarios at $5400 \mathrm{~s}$. It can be seen that development of the nodal displacements in the bottom chord of the structure was similar to those of the top chord of the structure. However, due to the restraint of the bottom chord resulted from directly connected to the column' supports, their displacements were comparatively smaller than the one in the top chord.

The displacement-time curves of the nodes of N3467 and N7425, which experienced the highest temperatures within the top and bottom chords are shown in Fig. 16. The locations of the nodes N3467 and N7425 are just above the fire source, as shown in Figs. 11 and 12. The vertical displacements of nodes N3467 and N7425 were changed from $-72.4 \mathrm{~mm}$ and $-71.4 \mathrm{~mm}$ to +101.6 $\mathrm{mm}$ and $+85.2 \mathrm{~mm}$, respectively after $5400 \mathrm{~s}$ of fire. The total displacement changes of them were up to $177.0 \mathrm{~mm}$ and $156.7 \mathrm{~mm}$, respectively. The maximum vertical negative displacements, positive displacements and the maximum displacement changes for the four fire scenarios are shown in Table 3. In the modelling the deformations and forces of each structural members were recorded. There was no buckling in any truss members observed during the structural simulation.

It can be seen that the key differences between fire scenarios in term of the displacements of the structure are: (1) for Fire Scenarios 1 and 2 there were considerable large maximum vertical downward and upward deflections. The displacement changes were relatively large during the fires. 
(2) for Fire Scenarios 3 and 4 there were relative small maximum vertical downward deflections and there were no upward deflections. The displacement changes were relatively small during the fires. This indicated that the influence of fire source area was greater than the location of fire source.

\subsection{The stresses of the structural members}

With the equivalent nodal loads, the structural performances of the exhibition centre at elevated temperatures were analysed. From the modelling results, it can be seen that the change of stresses of the structural members at elevated temperatures has a similar trend compared to the displacements. The stresses of the structural members were growing slowly during the initial and post fire periods, and developed rapidly during the mid-term of the fires. The structural members most prone to failure were the members right above the fire source and the supporting members near the fire source. The former one experienced the highest temperature and yielding earlier while the later one experienced the maximum stresses due to the strong restraint to the thermal expansion from the supporting members.

Figs 17 and 18 show the distribution of the stresses of the top and bottom chord members, respectively. The positions of the truss members with maximum stresses for both top and bottom chords were marked respectively in the figures.

The sections of the members with the highest temperature or the maximum stresses within the structure were regarded as the critical sections. Table 4 gives the stresses at the critical sections of the structure at both ambient and under various fire scenarios. In the table, the locations of critical sections were defined at the member with highest temperature (at highest temperature, see Fig. 15) or the member with highest stress (at highest stress, see Fig. 18) for different fire scenarios. Also the related temperature, yield strength of steel and the ratios of the stress with yield strengths at that temperature are presented in the table. In this study, the yield strengths of steel tube at elevated temperatures were calculated according to the model proposed by Yuan et al. [22].

After detailed examination of the stress situations within the structural members, it is clear that the key differences between fire scenarios in term of the stresses within the structural members of the 
structure are: (1) for Fire Scenarios 1 and 2 there were considerable large maximum stresses formed within the structural members during the fires and the maximum stresses reached $80-90 \%$ of yielding strength of steel. (2) for Fire Scenarios 3 and 4 there were relative small maximum stresses formed during the fires and the maximum stresses only reached below $70 \%$ of yielding strength of steel. This further supported that the influence of fire source area was greater than the location of fire source.

\subsection{Influences of different fire source locations}

The comparison of vertical displacements between different fire scenarios shows that the maximum downward (negative) displacements for Fire Scenarios 1 and 2 all occurred on the cantilever part of the top chord, as shown in Fig. 14. The magnitudes of the maximum downward displacement and upward (positive) displacement of Fire Scenario 1 were all bigger than that of Fire Scenario 2. Although the displacements of Fire Scenarios 3 and 4 were in the state of downward (negative) displacement after fire, however, the maximum change on the vertical displacement of Fire Scenario 3 was slightly greater than Fire Scenario 4.

To assess the stresses of structural members for different fire scenarios, it can be seen that the maximum stresses of the members for Fire Scenarios 1 and 2 all occurred on the bottom chord near the supporting columns. However, the magnitudes of the maximum stress and the maximum ratios of the stress with yield strengths for Fire Scenarios 1 were all bigger than that of Fire Scenario 2, as shown in Table 4. The comparison between Fire Scenario 3 and 4 was similar to that of Fire Scenarios 1 and 2. In conclusion, the fire located in the area with comparatively lower height within the larger space steel roof structure is more dangerous related to the structural performance. This is due to the fire source is more closed to the roof structure with a lower height. Hence, that part of the roof structure will have higher temperature during a fire.

For the exhibition centre with large space roof structures, due to the structural requirement, the height in the span of the structure near the boundary is always lower than that in the middle span. Therefore, if fire occurs in the area near the boundary like Fire Scenarios 1 in this study, the structural members right above the fire source will have higher temperatures. Moreover, this fire location is near the supporting columns and the fire will results a higher downward (negative) 
displacement of the cantilever part of the structure, and a larger stresses will be generated within the members near the supports. Hence, for large space structures, such as exhibition centre, avoid storing combustible goods near the external wall. For enhancing the fire resistance of the structure, the cross-section of the structural members near the supports needs to be properly increased in order to strengthen their load bearing capacity.

\subsection{Influences of different fire source areas}

To compare the vertical displacements between Fire Scenarios 1 and 2 (with the fire source area of $18 \times 18 \mathrm{~m}^{2}$ ) and Fire Scenarios 3 and 4 (with the fire source area of $9 \times 9 \mathrm{~m}^{2}$ ), it can be seen that the maximum changes of the vertical displacements of Fire Scenarios 1 and 2 all occurred at the nodes above the fire source, and reversed to the upward (positive) displacements after $2000 \mathrm{~s}$ of the fires. The changes of the displacements of the nodes in Fire Scenarios 3 and 4 were relatively small and the displacements were still in the state of downward (negative) displacement after $5400 \mathrm{~s}$ of the fire.

To analyse the stresses of the structural members for different fire scenarios, it is evident that the maximum stresses of the structural members for the four fire scenarios were all happened in the members near the supports. The maximum ratios of the stress with yield strength for Fire Scenarios 1 and 2 were $93 \%$ and $83 \%$, respectively. This indicates that the members right above the fire source area of Fire Scenarios 1 were almost yielded in which the highest temperature of the member was only $334{ }^{\circ} \mathrm{C}$. In contrast, the maximum ratios of the stress with yield strength for Fire Scenarios 3 and 4 were $67 \%$ and $54 \%$, respectively. This means that all the structural members were still in the elastic state with enough safety margins for load bearing capacity.

Based on the above analysis it can be concluded that the fires with the fire source area larger than $18 \times 18 \mathrm{~m}^{2}$ in the exhibition centre studied here can cause structural failure of the members near the supports or right above the fire source. For the fires with the fire source area less than $9 \times 9 \mathrm{~m}^{2}$ the structure performance of the exhibition centre was in the safe condition. The research indicated that large space steel structures can tolerate different fire conditions. Hence, it is important to adopt performance-based approach for the fire resistance design of large space steel structures. 


\subsection{Behaviour of the structure subjected to partial cooling}

For considering the safety of fire fighters, it is important to understand the behaviour of the structure subjected to partial cooling conditions. In this research the performance of the exhibition centre was reanalysed and when the fire duration of $5400 s$ was reached then partial cooling was applied to the structure. In this analysis, the most dangerous fire scenario (Fire Scenario 1) was used. For the partial cooling, it was assumed that the structural members right above the fire source area were instantly cooled to $20{ }^{\circ} \mathrm{C}$ by water. Based on this cooling condition, the displacements and stresses of the structure were analysed.

\subsubsection{Vertical displacements of the structure after cooling}

Fig. 19 shows the vertical displacement-time curves of the node N3467 (see Fig. 14(a) for the position) and node N7425 (see Fig. 15(a) for the position) within the top and bottom chords after partial cooling on that structural members. The rest of the structure was assumed to be at hot condition of fire time of $5400 \mathrm{~s}$. These two nodes on the top and bottom chords of the structure had the highest temperatures before cooling. From the figure it can be seen that the both nodal displacements were recovered immediately after the sudden water cooling. This is due to those steel members were still in the elastic stage at fire time of $5400 \mathrm{~s}$.

It can be seen that the changes of the displacements of two nodes were considerable different. For nodes $\mathrm{N} 3467$ and N7425, the displacements were changed from $102.2 \mathrm{~mm}$ and $93.9 \mathrm{~mm}$ to $69.6 \mathrm{~mm}$ and $70.8 \mathrm{~mm}$, respectively. This is due to the node N7425 was at the bottom chord and near the support. Hence, the members in the cooling zone were under more significant restraint from the surrounding members and less displacements' changes were generated. In contrast, the node N3467 was at the top chord and away from the supports, therefore more displacement's change was resulted from the cooling.

\subsubsection{The stresses of the structural members after cooling}

Table 5 presents the changes of the maximum stresses of four structural members at different locations within the top and bottom chords subjected to partial cooling. As mentioned above before the cooling the steel truss members were still in the elastic stage, the stresses of the structural 
members were significantly changed when the temperature of the members dropped to $20{ }^{\circ} \mathrm{C}$. For example, the maximum stress of the member E6507 (see Fig. 17(a) for position) in the top chord before cooling was 182.3 $\mathrm{MPa}$, and reduced to $48.4 \mathrm{MPa}$ after cooling. The maximum stress of the member E11706 (see Fig. 18(a) for position) in the bottom chord was $327.5 \mathrm{MPa}$ and recovered to 208.4 MPa after cooling.

However, it is interesting to note that the stresses of the members near the cooling zone in the top chord were increased sharply due to the impact of the cooling members. As shown in Table 5, the stress of member E8498 was increased considerable from 137.6 MPa before cooling to $226 \mathrm{MPa}$ after cooling. This phenomenon did not appear in the members within the bottom chord. This may be due to the influence of restraint provided by the supports which were connected to the bottom chord of the structure. It can be concluded that for the large roof steel truss structures, the water cooling of the members near the supports can lead to a sudden increase of the stresses in the structural members within top chord. This may contribute to the risk of the structural damage in the fire fighting stage. This should be considered in the structural fire engineering design of large roof steel truss structures.

\section{Conclusions}

This paper presents a comprehensive case study by using performance-based approach on the fire resistance of a large space exhibition centre in Shanxi province, China under the real fire scenarios including heating and cooling phases. The thermal and structural behaviour of the exhibition centre were modelled using FDS simulator and finite element software ANSYS. From this study some conclusions can be drawn as the following:

(1) The traditional ISO834 standard fire cannot be used for structural fire engineering design of large-space structures, such as the exhibition centre. Performance-based design approach is needed for the analysis of large steel truss roof structure in fire.

(2) The temperature field of the fire scenarios simulated by FDS shows that the space above the fire source area has the highest temperature, and gradually reduced for the spaces away from the fire source. For four different fire scenarios the highest fire temperatures were below 
$400{ }^{\circ} \mathrm{C}$. Both the location and the area of the fire source have considerable influence on the temperature field within the structures and the temperature field is non-uniform within the large space structure.

(3) The behaviours of the structure subjected to partial cooling conditions are also complex. The changes of the deformations and stresses of structural members are significantly affected by the partial cooling methods and the locations of the members within the structure. The stresses of the members near the cooling zone in the top chord can increased significantly due to the impact of the cooling members. In contrast, the stresses of the members in the bottom chord of the structure are changed less due to the provided supports. There have the possibilities of the structural damage in the fire fighting stage.

(4) In order to enhance the fire resistance of large-space steel truss structures, the following suggestions are proposed: (a) increase the cross-section of the structural member near the supports; (b) reduce the outrigger dimension of the structure; (c) avoid piling combustible goods near the corner of supports during service period of the structure; (4) control the area of the fire source and arrange high exhibition platform in the high space zone.

(5) This research presented a comprehensive demonstration to show how fire resistance of a large-space steel truss structure can be assessed based on performance-based fire design approach step by step. The information presented in this paper is useful for practical structural engineers for conducting the fire resistance design of a complex large space steel structure.

\section{Acknowledgements}

This research was supported by the 2017 Research Found for Youth Science and Technology of China University of Mining and Technology (JB179064) and the 2012 Specialized Research Fund for the Doctoral Program of Higher Education of China (Grant No. 20120095110027). The authors gratefully appreciate these supports. 


\section{References}

1. Huang, J.Q., Li, G.Q. Du, Y. The revision of two-zone fire model calculating the air temperature in large space buildings. Fire Science and Technology, 2005, 3: 279-283.

2. Zhang, C., Li, G.Q. Simple formulae for calculating the gas temperature in large enclosure fire environment. Fire Safety Science, 2012, 21(2):84-91.

3. Taerwe, L., Bamonte, P., Both, K., Denoël, J.F., Diederichs, U., Dotreppe, J.C., Felicetti, R., Fellinger, J., Franssen, J. M., Gambarova, P.G., Hoj, N.P., lennon, T., Meda, A., Msaad, Y., Ozbolt, J., Periskic, G., Riva, P., Robert, F., Van Acker, A. Fire design of concrete structures-structural behaviour and assessment, State-of-the-art report, fib bulletin 46, International Federation for Structural Concrete (fib TG 4.3.2), Lausanne, 2008.

4. Richard L., Tang L., Choo, Y.S. Advanced analysis for performance-based design of steel structures exposed to fires. Journal of Structure Engineer, 2002, 12: 1584-1594.

5. Buchanan, A. H. Fire Engineering Design Guide. New Zealand: 2001.

6. Du, Y., Li, G.Q. A new temperature-time curve for fire-resistance analysis of structures, Fire Safety Journal, 2012, 54(1):113-120.

7. Xue, S.D., Xiong, J.L., Li, Y. Empirical formula for air temperature in large space structure under fire. Journal of Beijing University of Technology, 2013, 39(2): 203-207.

8. Fan, S., Shu, G.P., She, G.J., Liew J.Y.R. Computational method and numerical simulation of temperature field for large-space steel structures in fire. Advanced Steel Construction, 2014, 10(2): 151-178.

9. McGrattan, K., McDermott, R., Hostikka, S., Floyd J. Fire Dynamics Simulator (Version 5) User's Guide. USA, NISTIR, 2010.

10. Liu M., Zhao J., Sun C., Wang F. Anti-fire experiment and finite element analysis of steel planar circular tubular truss, Low Temperature Architecture Technology, 2012, (2): 27-29.

11. Zhao J.S., Shen W.P. Nonlinear F.E. analysis of steel frames at elevated temperatures, Journal of Shanghai Jiao Tong University, 1996, 30(8): 55-59.

12. Li, G.Q. Wang P.J. Wang Y.C. Behavior and design of restrained steel column in fire. Part2: Fire Test, Journal of Constructional Steel Research, 2010, 66: 1148-1154.

13. Li, G.Q. Wang P.J. Wang Y.C. Behavior and design of restrained steel column in fire. Part1: Parameter study, Journal of Constructional Steel Research, 2010, 66: 1138-1147.

14. Yin Y.Z., Wang Y.C. Analysis of catenary in steel beams using a simplified hand calculation method, Part 1: theory and validation for uniform temperature distribution. Journal of Constructional Steel Research, 2005, 61:183-211.

15. Yin Y.Z, Wang Y.C. A numerical study of large deflection behavior of restrained steel beams at elevated temperatures. Journal of Constructional Steel Research. 2004, 60:1029-1047.

16. Chinese code for fire protection design of buildings (GB 50016-2014). China Planning Press, Beijing, 2014 (in Chinese).

17. Technical specification for fire protection of steel structure buildings (CECS 200-2006). Beijing: China Planning Press, 2006.

18. Standard for Smoke and Heat Venting (ANSI/NFPA 204-2006), USA, 2006. 
19. Hu, L.H., Fong, N.K., Yang, L.Z., Chow, W.K., Li, Y.Z., Huo, R. Modeling fire-induced smoke spread and carbon monoxide transportation in a long channel: Fire Dynamics Simulator comparisons with measured data. Journal of Hazardous Materials, 2007, 140: 293-298.

20. Ding, J., Wang, Y.C. Realistic modelling of thermal and structural behaviour of unprotected concrete filled tubular columns in fire. Journal of Constructional Steel Research, 2008, 64: 1086-1102.

21. Kodur, V., Dwaikat, M., Fike, R. High-temperature properties of steel for fire resistance modeling of structures. Journal of Materials in Civil Engineering, 2010, 22(5): 423-434.

22. Yuan G., Shu Q., Huang Z., and Li Q. “An experimental investigation of properties of Q345 steel pipe at elevated temperatures", Journal of Constructional Steel Research, 2016, 118: 41-48.

23. Chinese code for design of steel structures (GB 50017-2003). China Planning Press, Beijing, 2003 (in Chinese).

24. CEN, Eurocode 3: design of steel structures, part 1-2, Structural fire design, European Committee for Standardization, BS EN 1993-1-2, 2005. 


\section{Captions of figure and tables}

Table 1 Fire scenarios used in this study.

Table 2 The specifications of the structural members used in the FE model.

Table 3 Maximum vertical displacements of the members under different fire scenarios.

Table 4 The stresses at the critical sections of the structure under various fire scenarios.

Table 5 The changes of the maximum stresses of four structural members at different locations after partial cooling.

Fig. 1 A 52,000 $\mathrm{m}^{2}$ exhibition centre located in Taiyuan, Shanxi Province, China.

Fig. 2 The floor layout of the exhibition centre.

Fig. 3 The locations of the fire sources within the exhibition centre.

Fig. 4 Fire development curve with the decay period ignored.

Fig. 5 Fire simulation model established using FDS.

Fig. 6 Predicted smoke and gas distributions of Fire Scenarios 1 and 3.

Fig. 7 Predicted temperature distributions of Fire scenarios 1 and 3 (at height $=12 \mathrm{~m}$ ).

Fig. 8 Predicted smoke and gas distributions of Fire scenarios 2 and 4.

Fig. 9 Predicted temperature distributions of Fire scenarios 2 and 4 (at height $=12 \mathrm{~m}$ ).

Fig. 10 The structural model of the exhibition hall simulated by ANSYS.

Fig. 11 Calculated temperature distributions of the structural members for different fire scenarios.

Fig. 12 Calculated temperatures of the truss members at different positions related to the fire source for different fire scenarios.

Fig. 13 The support conditions of the structure.

Fig. 14 The vertical nodal displacement contours in the top chord of the steel truss structure for four fire scenarios at $5400 s$ fire time.

Fig. 15 The vertical nodal displacement contours in the bottom chord of the steel truss structure for four fire scenarios at $5400 s$ fire time.

Fig. 16 The vertical displacement-time curves of the nodes N3467 and N7425, which experienced the highest temperatures within the top and bottom chords.

Fig. 17 The stresses of the members on the top chord of the steel truss structure for four fire scenarios at $5400 s$ fire time.

Fig. 18 The Stresses of the members on the bottom chord of the steel truss structure for four fire scenarios at $5400 s$ fire time.

Fig. 19 The vertical displacement-time curves of the nodes N3467 and N7425 within the top and bottom chords after partial cooling. 


\section{List of tables}

Table 1 Fire scenarios used in this study.

\begin{tabular}{c|c|c|c|c|c|c}
\hline $\begin{array}{c}\text { Fire } \\
\text { scenario }\end{array}$ & $\begin{array}{c}\text { Fire source location } \\
\text { (see Fig. 2) }\end{array}$ & Fire source & $\alpha$ & $\begin{array}{c}\text { Density of HRR } \\
\left(\mathrm{kW/m^{2 }}\right)\end{array}$ & $\begin{array}{c}\text { Fire source area } \\
(\mathrm{m} \times \mathrm{m})\end{array}$ & $\begin{array}{c}\text { Fire fighting } \\
\text { system }\end{array}$ \\
\hline 1 & Near outer wall ( A ) & $\begin{array}{c}\text { Exhibition } \\
\text { items }\end{array}$ & Fast fire & 100 & $18 \times 18$ & Out of work \\
\hline 2 & Near mid-span ( B ) & $\begin{array}{c}\text { Exhibition } \\
\text { items }\end{array}$ & Fast fire & 100 & $18 \times 18$ & Out of work \\
\hline 3 & Near outer wall ( A ) & $\begin{array}{c}\text { Exhibition } \\
\text { items }\end{array}$ & Fast fire & 100 & $9 \times 9$ & Out of work \\
\hline
\end{tabular}

Table 2 The specifications of the structural members used in the FE model.

\begin{tabular}{c|c|c|c|c|c}
\hline $\begin{array}{c}\text { Element } \\
\text { number }\end{array}$ & $\begin{array}{c}\text { Tuble } \\
\text { cross-section }\end{array}$ & $\begin{array}{c}\text { Element } \\
\text { number }\end{array}$ & $\begin{array}{c}\text { Tuble } \\
\text { cross-section }\end{array}$ & Element number & $\begin{array}{c}\text { Tuble } \\
\text { cross-section }\end{array}$ \\
\hline $1-2$ & $\Phi 245 \times 12$ & 16129 & $\Phi 800 \times 20$ & 16721 & $\Phi 203 \times 8$ \\
\hline $3-17$ & $\Phi 351 \times 12$ & 16241 & $\Phi 600 \times 16$ & $16722-16723$ & $\Phi 180 \times 10$ \\
\hline $18-26$ & $\Phi 500 \times 16$ & 16353 & $\Phi 600 \times 16$ & $20609-20611$ & $\Phi 203 \times 8$ \\
\hline $27-32$ & $\Phi 351 \times 12$ & 16465 & $\Phi 600 \times 16$ & $20612-20618$ & $\Phi 140 \times 8$ \\
\hline $33-36$ & $\Phi 245 \times 8$ & 16577 & $\Phi 402 \times 10$ & $20619-20631$ & $\Phi 102 \times 5$ \\
\hline 8065 & $\Phi 800 \times 35$ & $16689-16690$ & $\Phi 180 \times 10$ & $20632-20639$ & $\Phi 140 \times 8$ \\
\hline 8177 & $\Phi 402 \times 16$ & 16691 & $\Phi 203 \times 8$ & $20640-20642$ & $\Phi 203 \times 8$ \\
\hline 8289 & $\Phi 402 \times 16$ & $16692-16699$ & $\Phi 180 \times 10$ & 20643 & $\Phi 299 \times 10$ \\
\hline 8401 & $\Phi 402 \times 16$ & $16700-16711$ & $\Phi 102 \times 5$ & & \\
\hline $8513-8546$ & $\Phi 351 \times 10$ & $16712-16720$ & $\Phi 180 \times 10$ & & \\
\hline
\end{tabular}


Table 3 Maximum vertical displacements of the members under different fire scenarios.

\begin{tabular}{c|c|c|c|}
\hline Fire scenario & $\begin{array}{c}\text { Max. downward } \\
\text { displacement }(\mathrm{mm})\end{array}$ & $\begin{array}{c}\text { Max. upward displacement } \\
(\mathrm{mm})\end{array}$ \\
\hline 1 & -137.5 & +102.3 & 174.0 \\
\hline 2 & -115.7 & +80.1 & 62.5 \\
\hline 3 & -75.9 & - & 59.9 \\
\hline
\end{tabular}

Table 4 The stresses at the critical sections of the structure under various fire scenarios.

\begin{tabular}{c|c|c|c|c|c|c}
\hline $\begin{array}{c}\text { Fire } \\
\text { scenarios }\end{array}$ & $\begin{array}{c}\text { Location of } \\
\text { critical section }\end{array}$ & $\begin{array}{c}\mathrm{S}\left(20{ }^{\circ} \mathrm{C}\right) \\
(\mathrm{MPa})\end{array}$ & $\begin{array}{c}\mathrm{S}(\mathrm{T}) \\
(\mathrm{MPa})\end{array}$ & $\mathrm{T}\left({ }^{\circ} \mathrm{C}\right)$ & $\begin{array}{c}\mathrm{YS}(\mathrm{T}) \\
(\mathrm{MPa})\end{array}$ & $\mathrm{S}(\mathrm{T}) / \mathrm{YS}(\mathrm{T})$ \\
\hline \multirow{2}{*}{1} & At highest T & 12.1 & 269.1 & 334.4 & 288 & 0.93 \\
\cline { 2 - 7 } & At highest S & 93.1 & 327.4 & 75.7 & 356 & 0.92 \\
\hline \multirow{2}{*}{2} & At highest T & 26.2 & 227.8 & 292.6 & 295 & 0.77 \\
\cline { 2 - 7 } & At highest S & 93.0 & 295.5 & 30.4 & 356 & 0.83 \\
\hline \multirow{3}{*}{3} & At highest T & 12.1 & 198.4 & 240.2 & 298 & 0.67 \\
\cline { 2 - 7 } & At highest S & 93.1 & 219.0 & 40.8 & 356 & 0.62 \\
\hline \multirow{2}{*}{4} & At highest T & 26.2 & 160.5 & 211.2 & 300 & 0.54 \\
\cline { 2 - 7 } & At highest S & 93.0 & 166.7 & 21.2 & 356 & 0.47 \\
\hline
\end{tabular}

Notes: $\mathrm{S}$ is short for stress; YS is short for the yielding strength of steel; $\mathrm{T}$ is short for temperature. 
Table 5 The changes of the maximum stresses of four structural members at different locations after partial cooling.

\begin{tabular}{c|c|c|c|c}
\hline No. of the members & E6507 (top chord) & E8498 (top chord) & E11706 (bottom chord) & E11842 (bottom chord) \\
\hline $\begin{array}{c}\text { Stress before cooling } \\
(\mathrm{MPa})\end{array}$ & 182.3 & 137.6 & 327.5 & 312.5 \\
\hline $\begin{array}{c}\text { Stress after cooling } \\
(\mathrm{MPa})\end{array}$ & 48.4 & 226.0 & 208.4 & 312.5 \\
\hline
\end{tabular}




\section{List of figures}

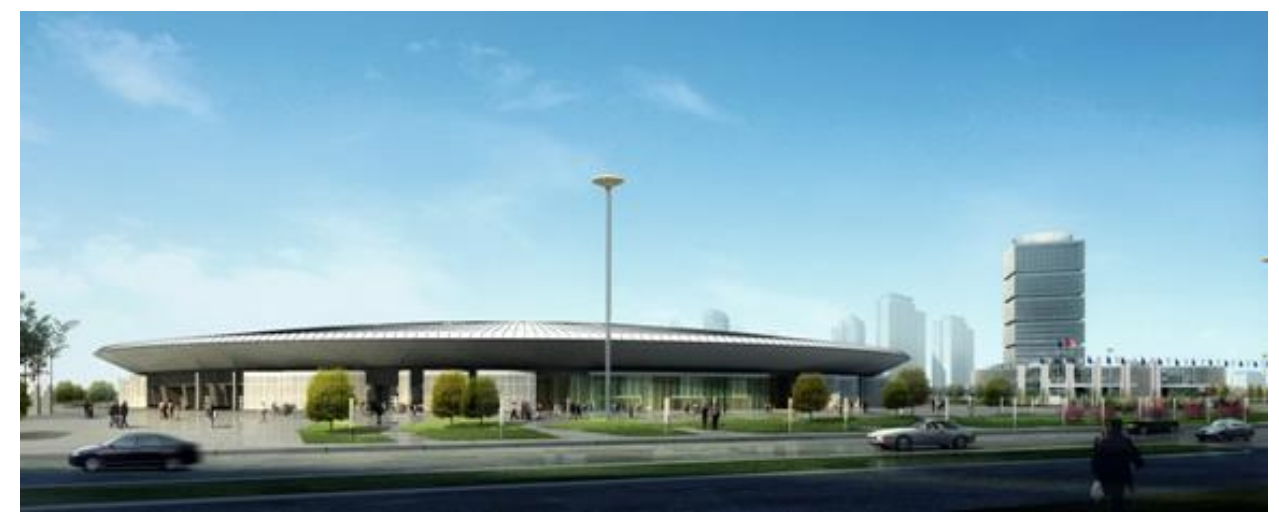

Fig. 1 A 52,000 $\mathrm{m}^{2}$ exhibition centre located in Taiyuan, Shanxi Province, China.

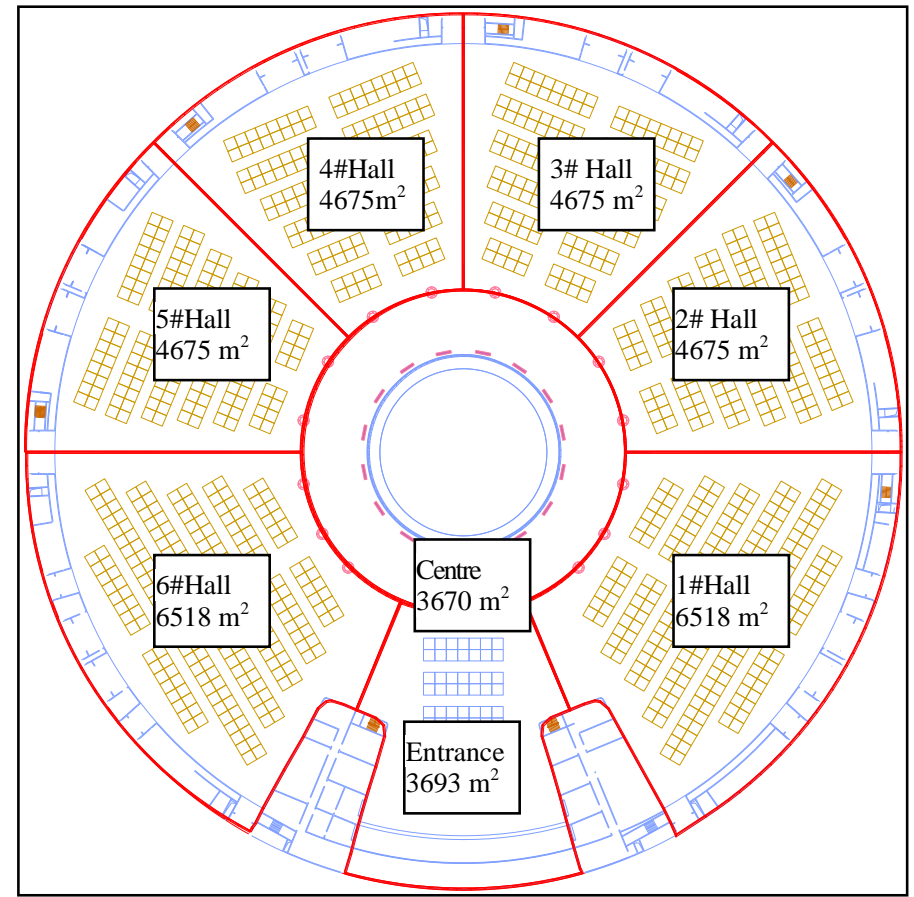

Fig. 2 The floor layout of the exhibition centre. 


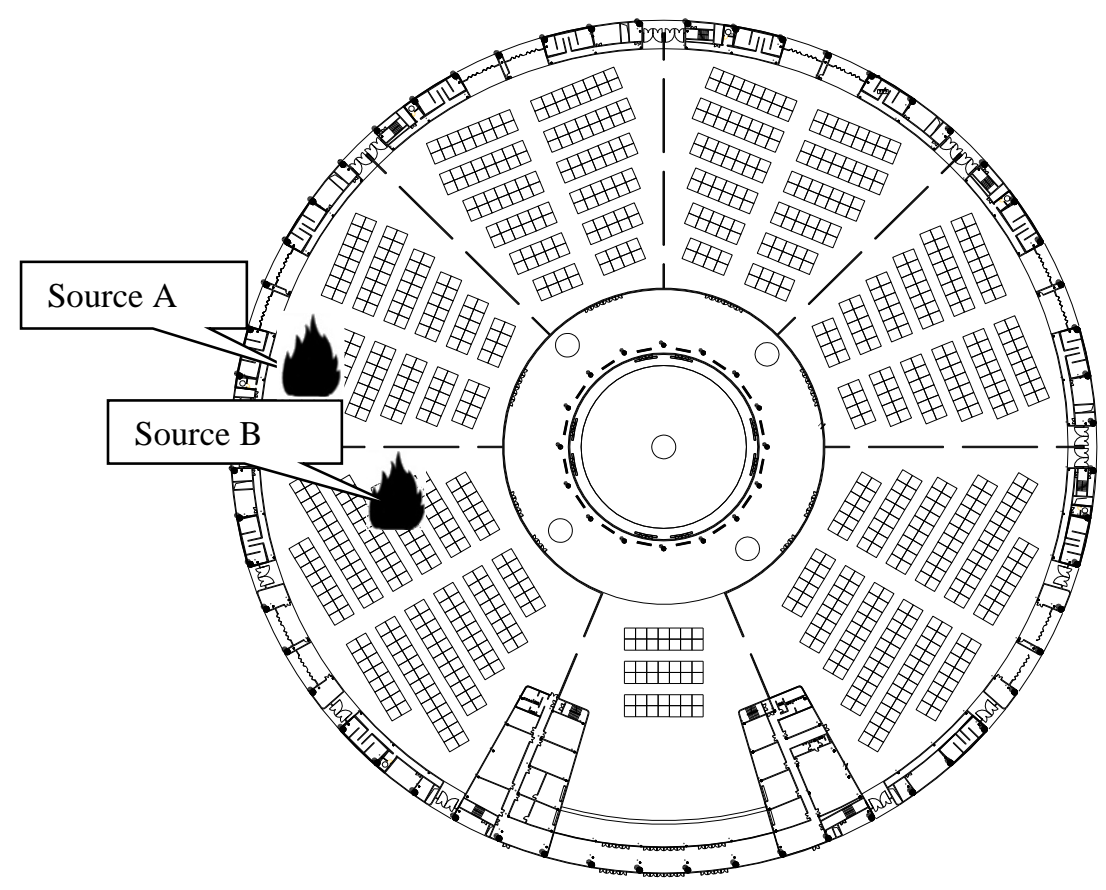

Fig. 3 The locations of the fire sources within the exhibition centre.

Heat release rate, $Q_{f}$

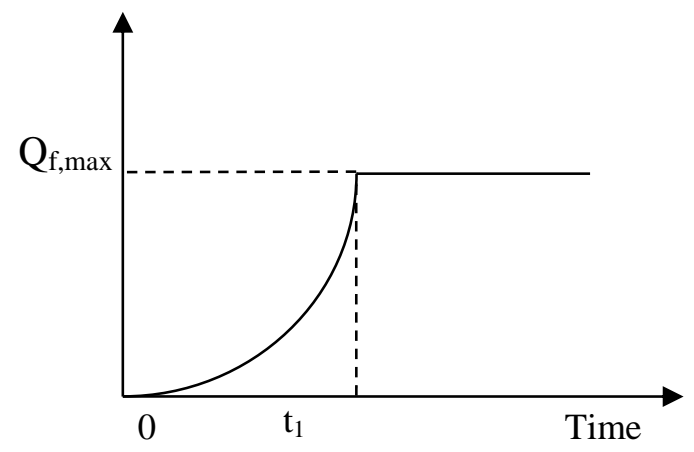

Fig. 4 Fire development curve with the decay period ignored. 


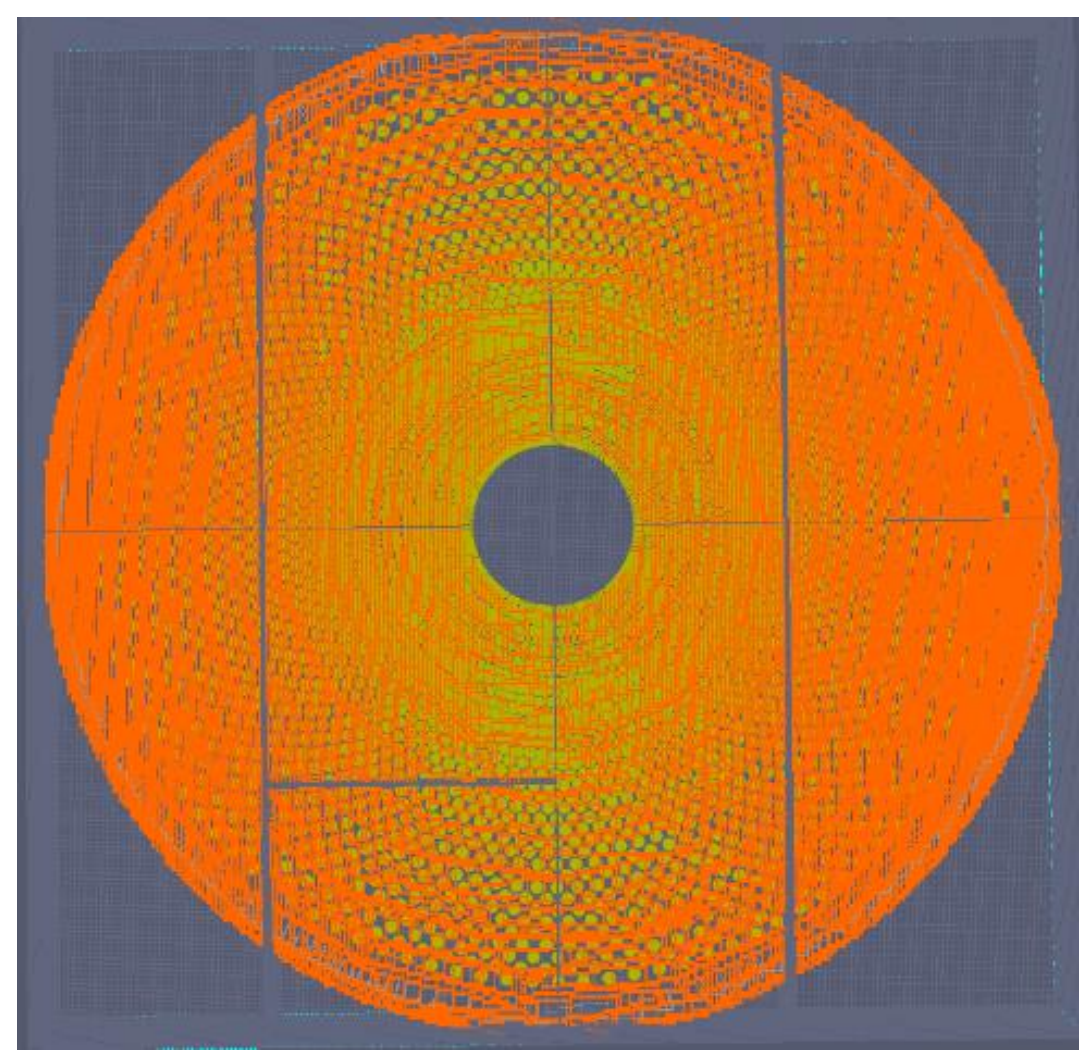

(a) Plane view of the model

(b) Elevation view of the model

Fig. 5 Fire simulation model established using FDS. 


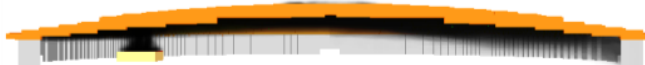

$\substack{\text { fame co } \\ \text { the con }}$

Frame: 540
Time: 5400.0

(a) Fire Scenario 1 at $600 \mathrm{~s}$

(b) Fire Scenario 1 at $5400 s$
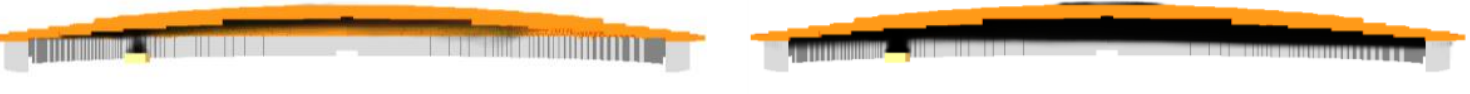

Frame: 60
Time: 600.0

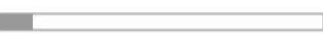

Frame: 540
Time: 5400.

(c) Fire Scenario 3 at $600 s$

(d) Fire Scenario 3 at $5400 s$

Fig. 6 Predicted smoke and gas distributions of Fire Scenarios 1 and 3. 


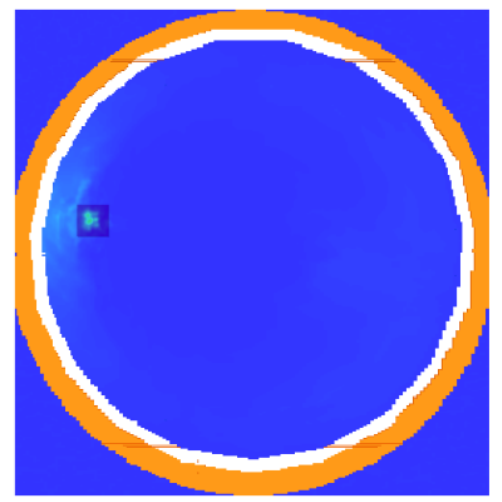

Frame: 60
Time: 600.0 단

(a) Fire Scenario 1 at $600 s$

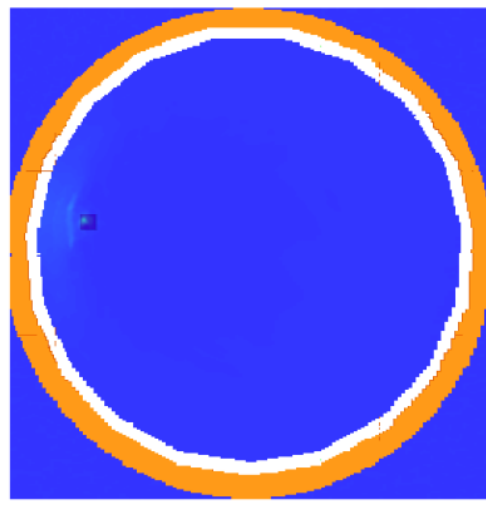

Frame: 60
Time: 600.0

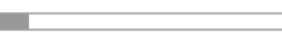

(c) Fire Scenario 3 at $600 s$
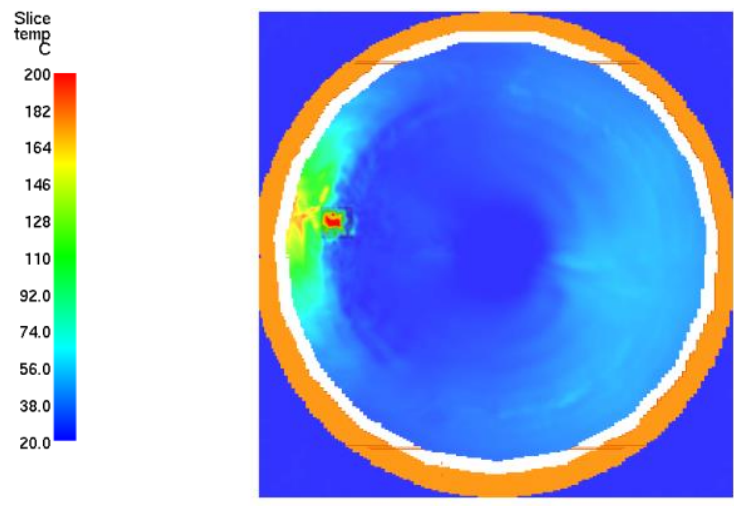

Slice

200

182
164

146

128

1

56.0
38.0

Frame: 540
Time: 5400.0

20.0

(b) Fire Scenario 1 at $5400 \mathrm{~s}$

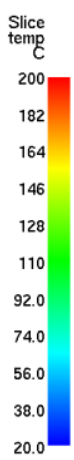

Frame: $\mathbf{5 4 0}$
Time: $\mathbf{5 4 0 0 . 0}$

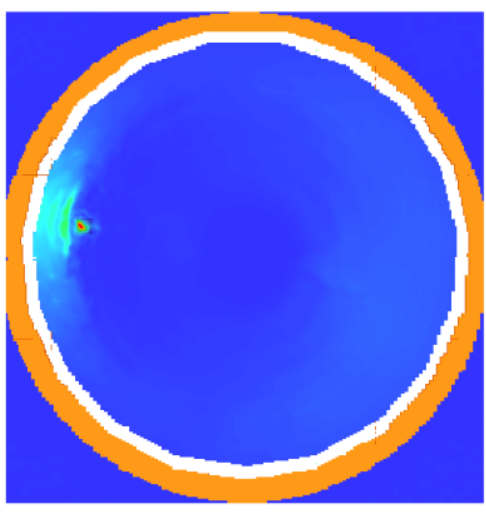

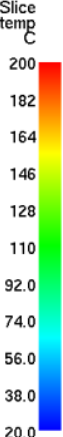

(d) Fire Scenario 3 at $5400 s$

Fig. 7 Predicted temperature distributions of Fire scenarios 1 and 3 (at height $=12 \mathrm{~m}$ ). 


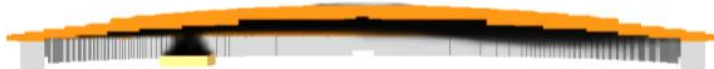

Frame: 60
Time: 600.0

(a) Fire Scenario 2 at $600 \mathrm{~s}$

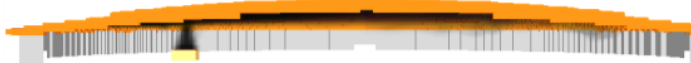

Frame: 60
Time: 600.0

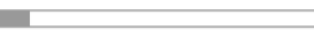

(c) Fire Scenario 4 at $600 s$

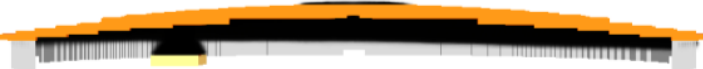

Frame: 540

Time: 5400.

(b) Fire Scenario 2 at $5400 s$

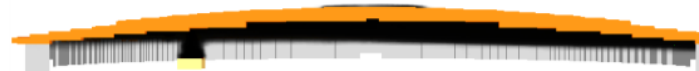

Frame: 540

(d) Fire Scenario 4 at $5400 s$

Fig. 8 Predicted smoke and gas distributions of Fire scenarios 2 and 4. 


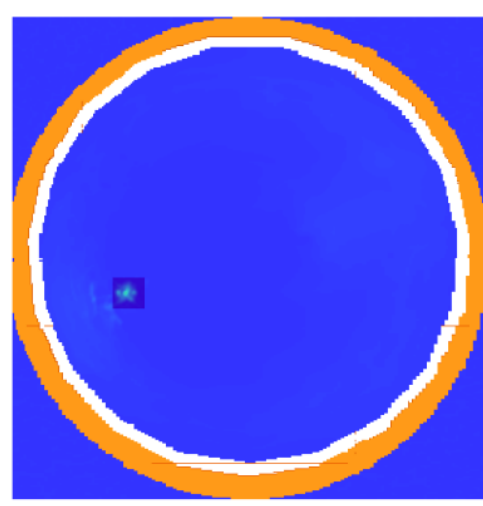

Frame: 60
Time: 600.1

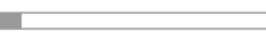

(a) Fire Scenario 2 at $600 \mathrm{~s}$

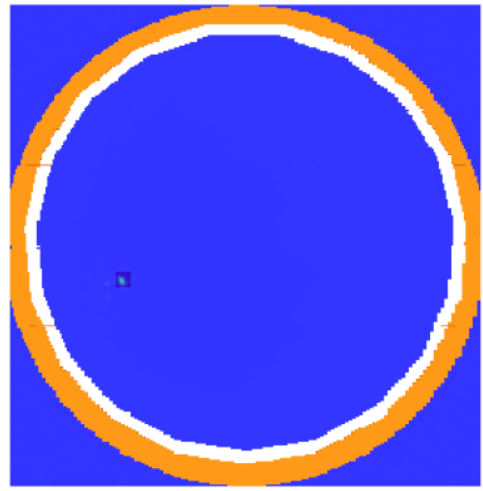

Frame: 60
Time: 600.0

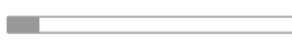

(c) Fire Scenario 4 at $600 s$
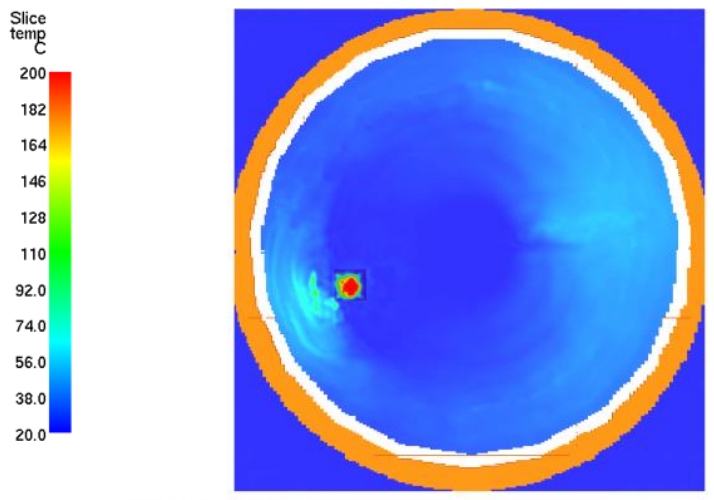

Slice

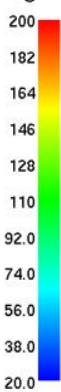

Frame: $\mathbf{5 4 0}$
Time: $\mathbf{5 4 0 0 . 0}$

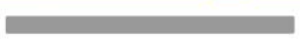

(b) Fire Scenario 2 at $5400 s$
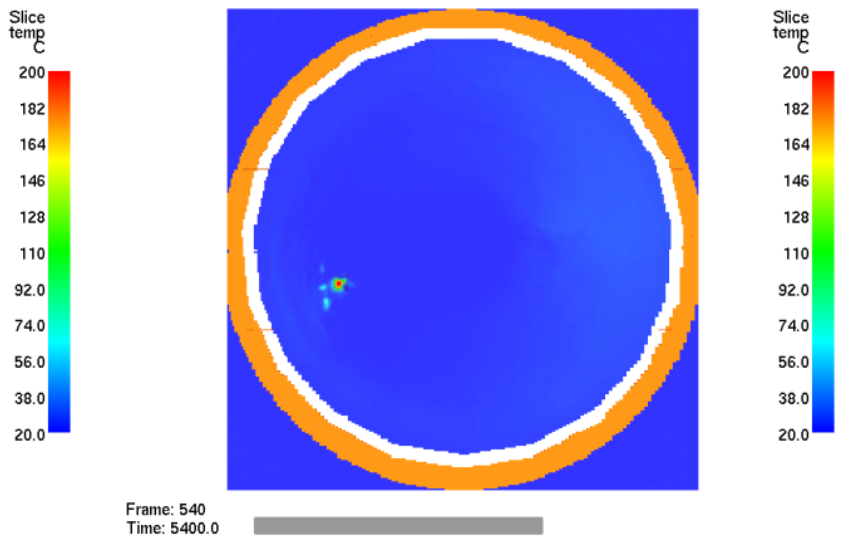

(d) Fire Scenario 4 at $5400 s$

Fig. 9 Predicted temperature distributions of Fire scenarios 2 and 4 (at height $=12 \mathrm{~m}$ ). 


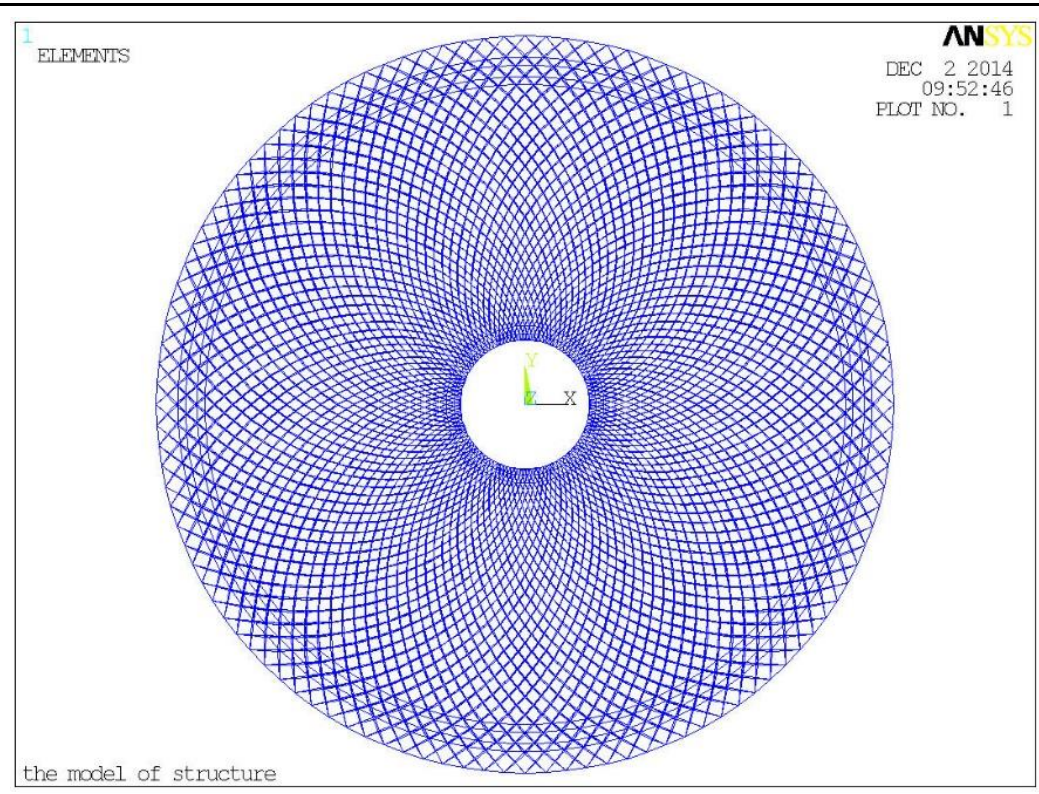

(a) Plane view of the model

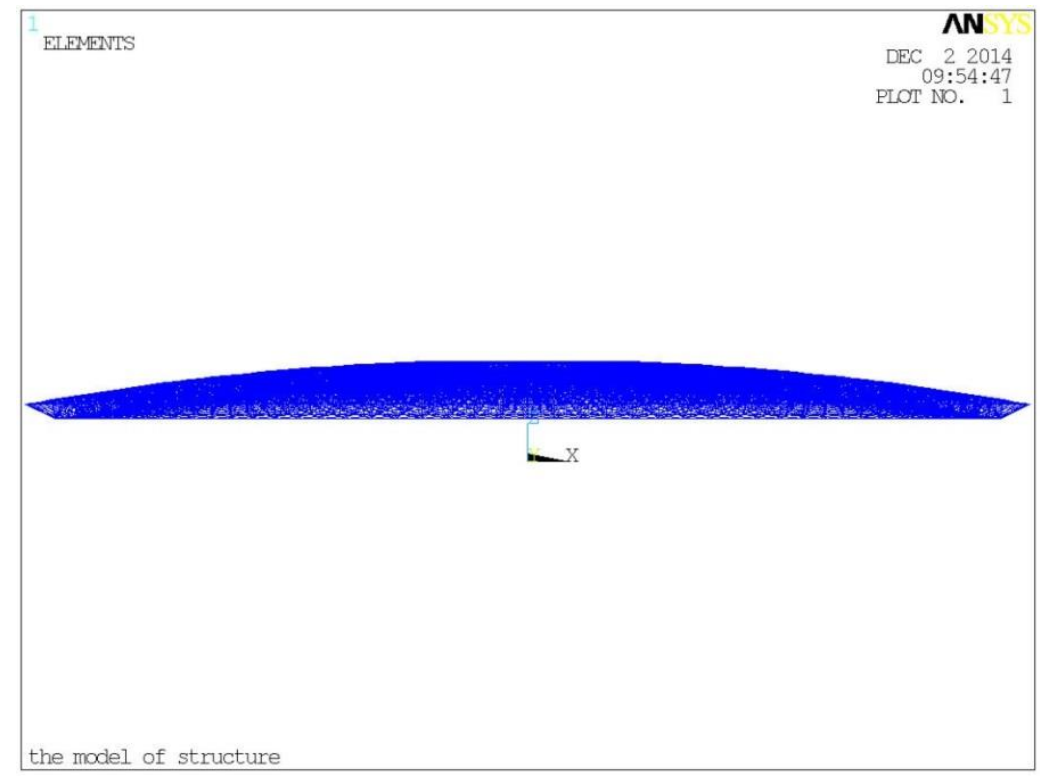

(b) Elevation view of the model 


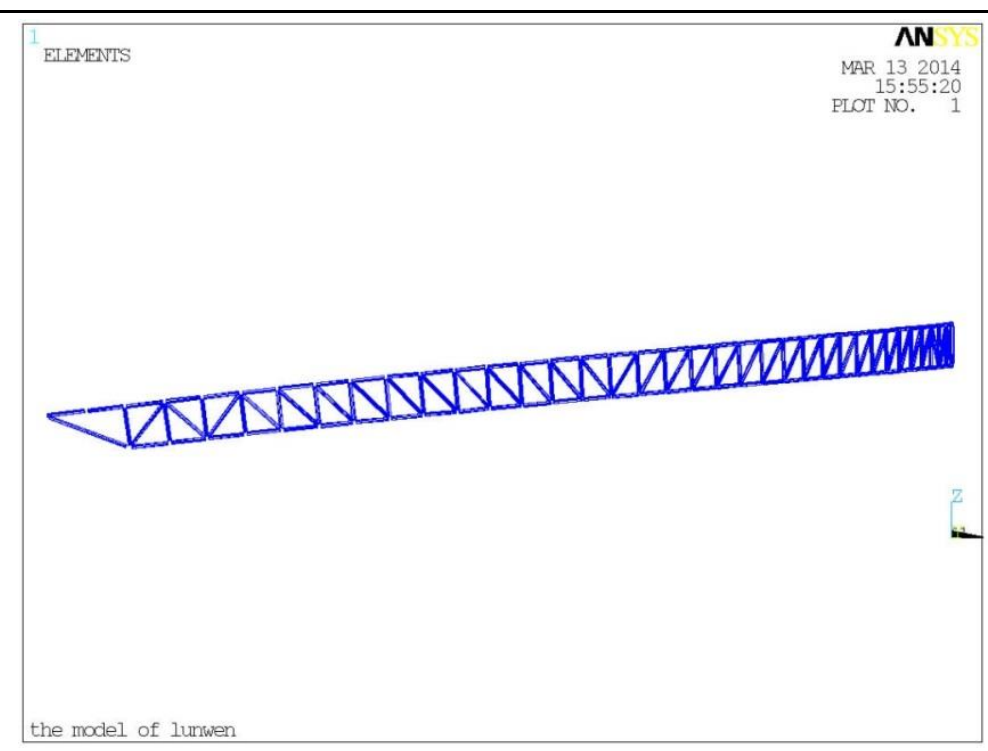

(c) Schematic diagram of a typical truss girder

Fig. 10 The structural model of the exhibition hall simulated by ANSYS. 


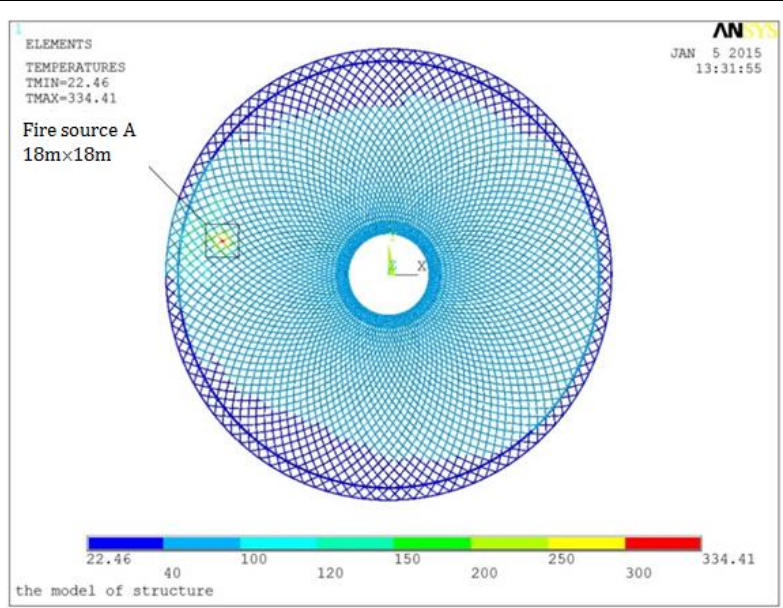

(a) Fire Scenario 1 at $5400 s$

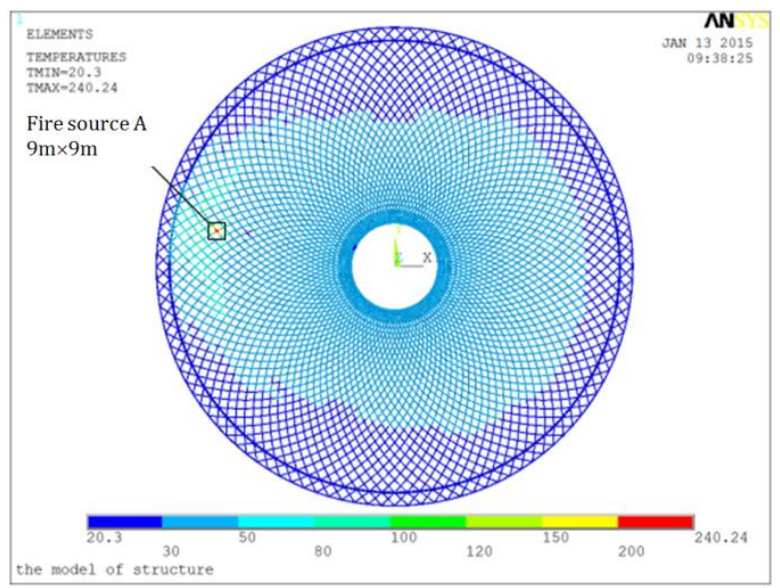

(c) Fire Scenario 3 at $5400 \mathrm{~s}$

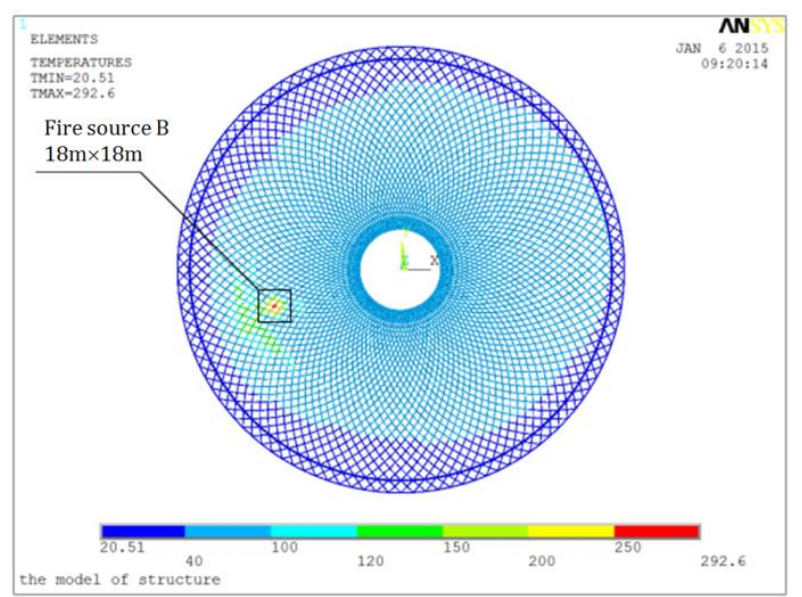

(b) Fire Scenario 2 at $5400 \mathrm{~s}$

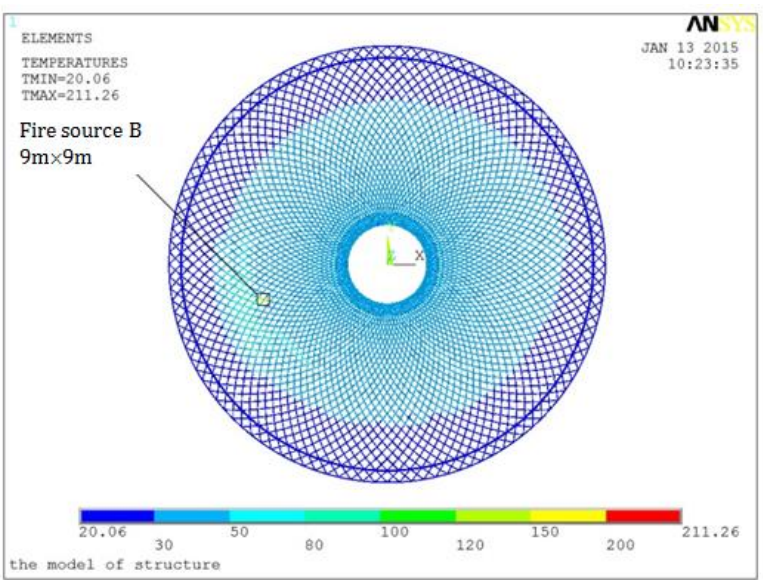

(d) Fire Scenario 4 at $5400 s$

Fig. 11 Calculated temperature distributions of the structural members for different fire scenarios.

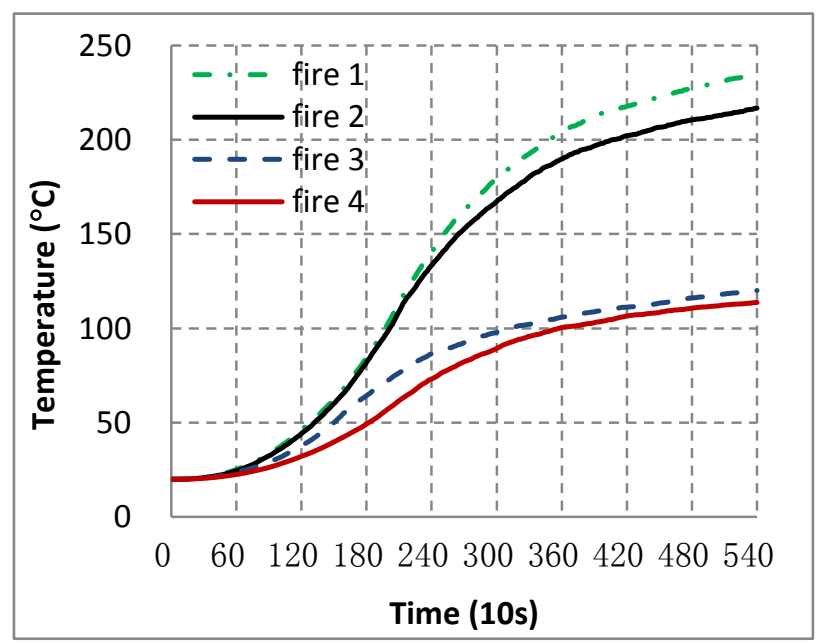

(a) Truss member at Position E1

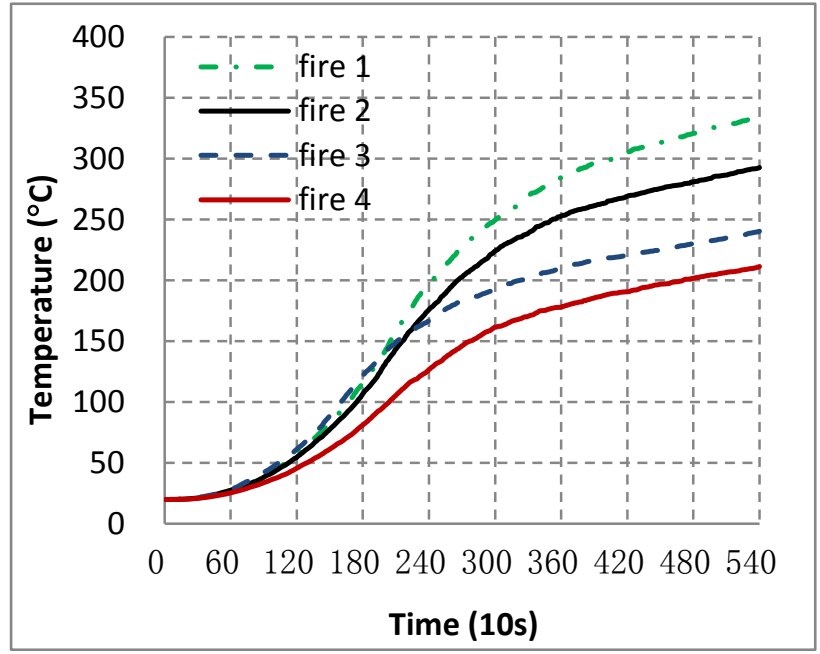

(b) Truss member at Position E2 


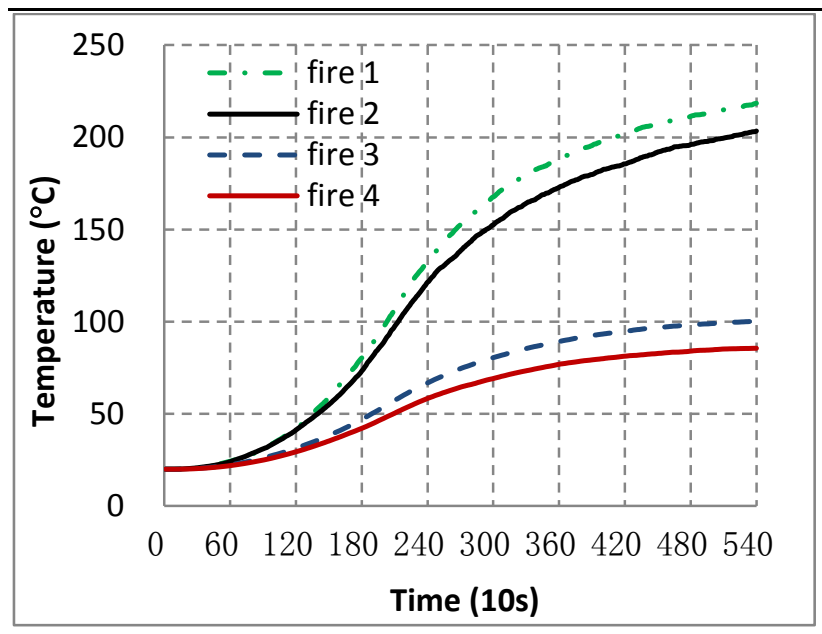

(c) Truss member at Position E3

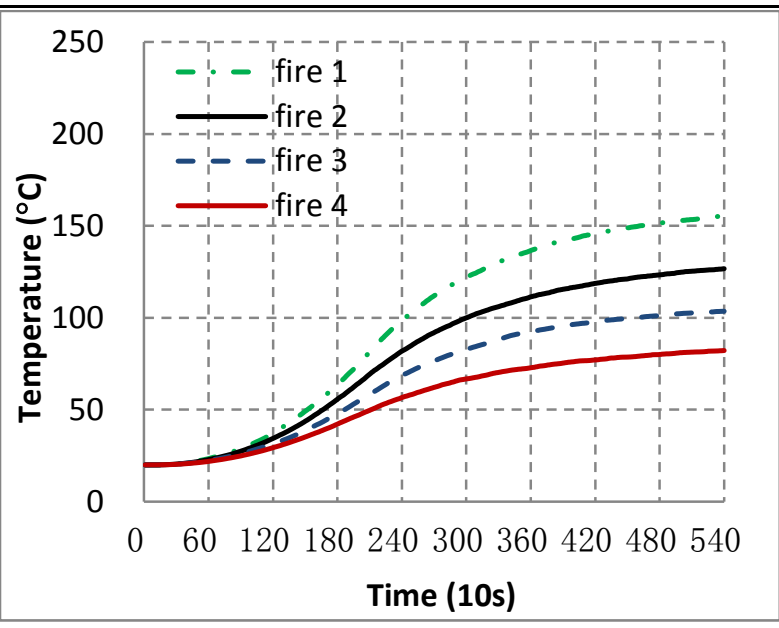

(d) Truss member at Position E4

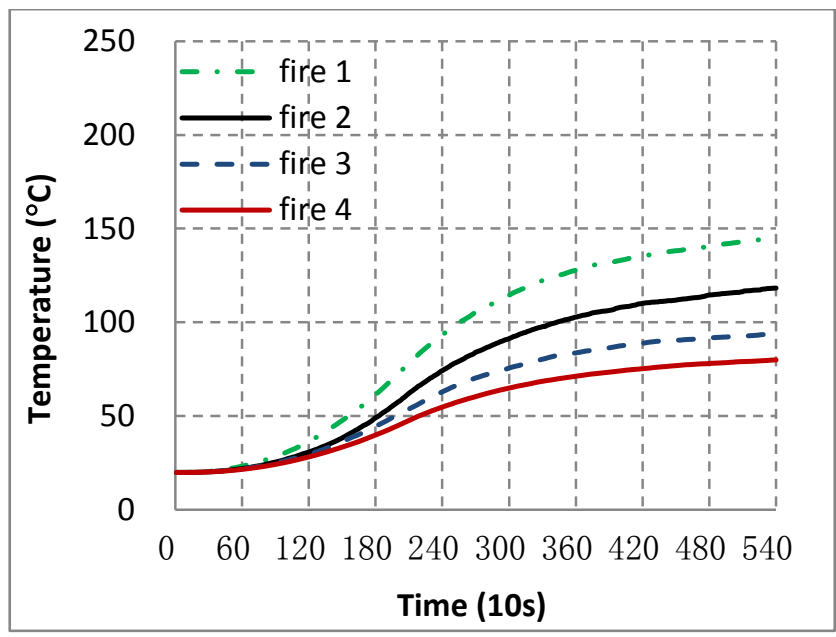

(e) Truss member at Position E5

Fig. 12 Calculated temperatures of the truss members at different positions related to the fire source for different fire scenarios.

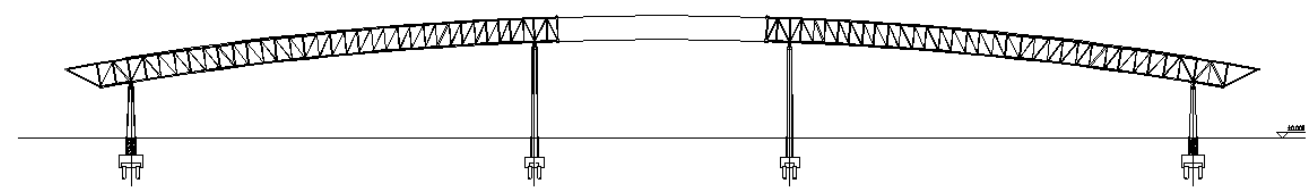

( a ) Elevation 


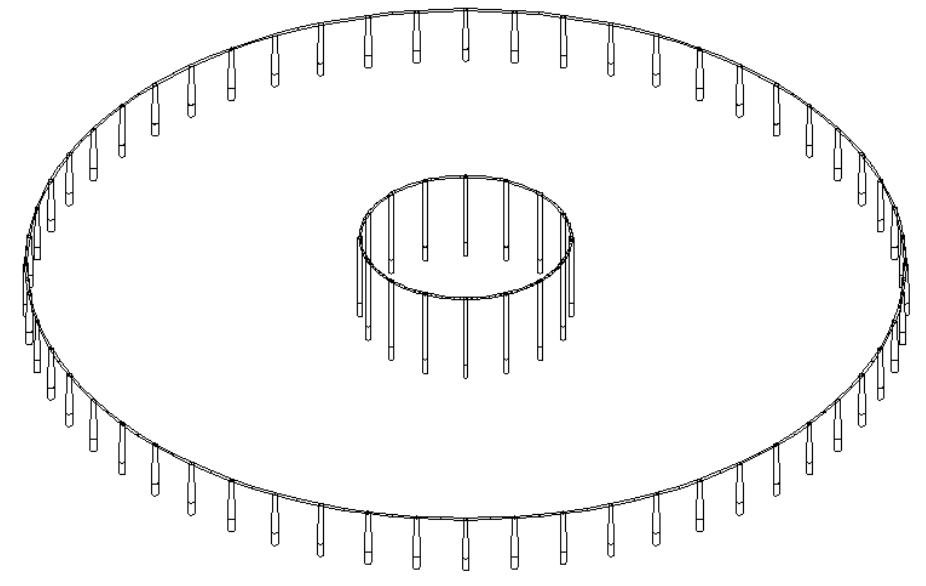

( b ) layout

Fig. 13 The support conditions of the structure.

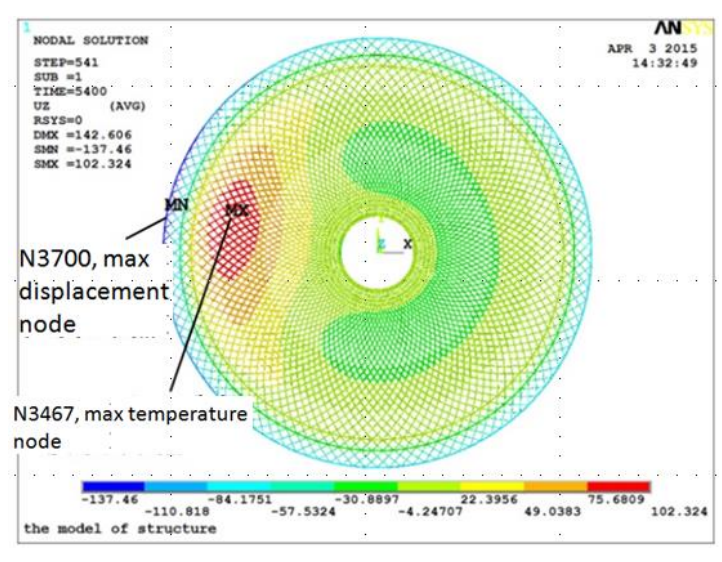

(a) Fire Scenario 1

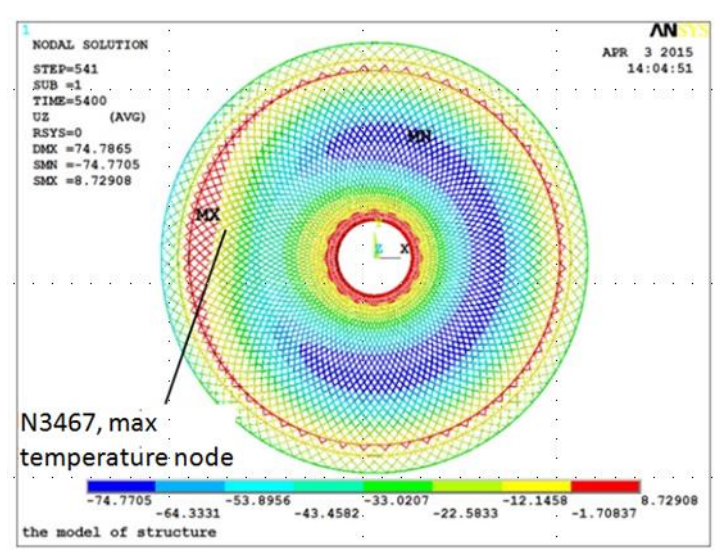

(c) Fire Scenario 3

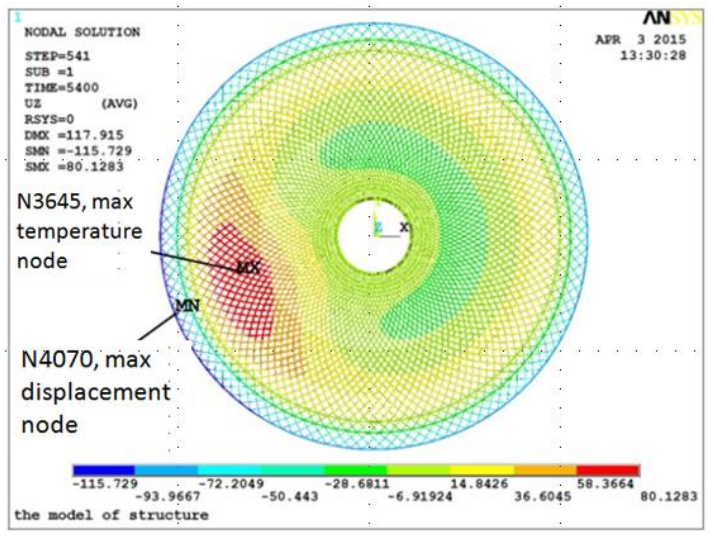

(b) Fire Scenario 2

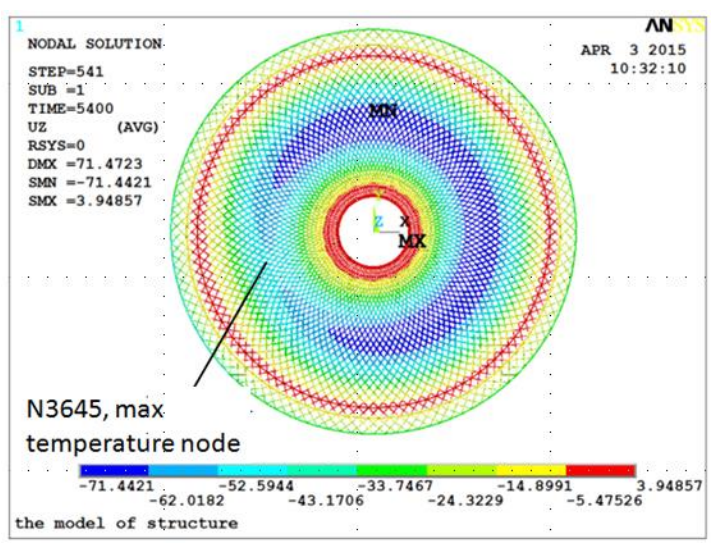

(d) Fire Scenario 4

Fig. 14 The vertical nodal displacement contours in the top chord of the steel truss structure for four fire scenarios at $5400 s$ fire time. 


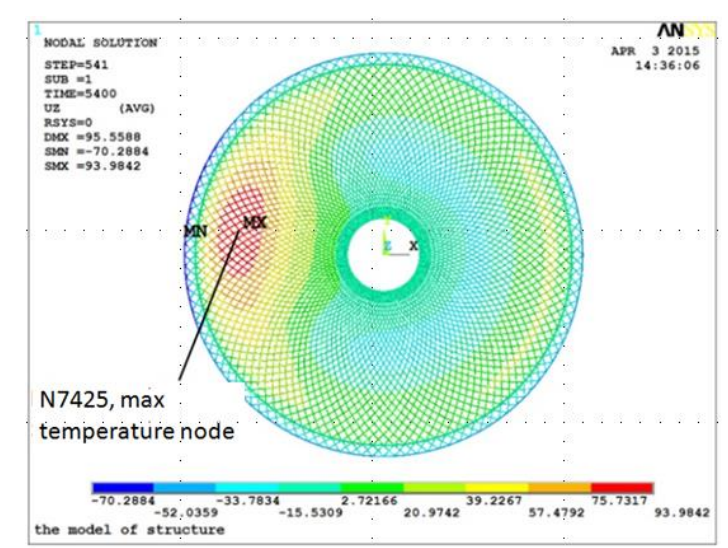

(a) Fire Scenario 1

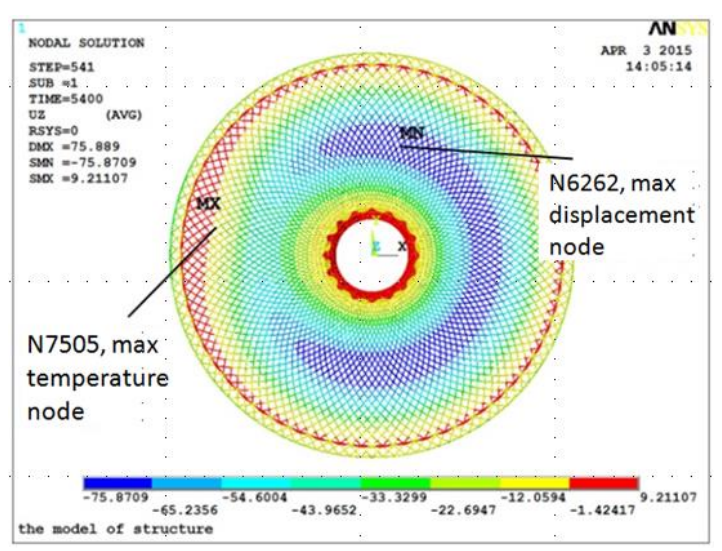

(c) Fire Scenario 3

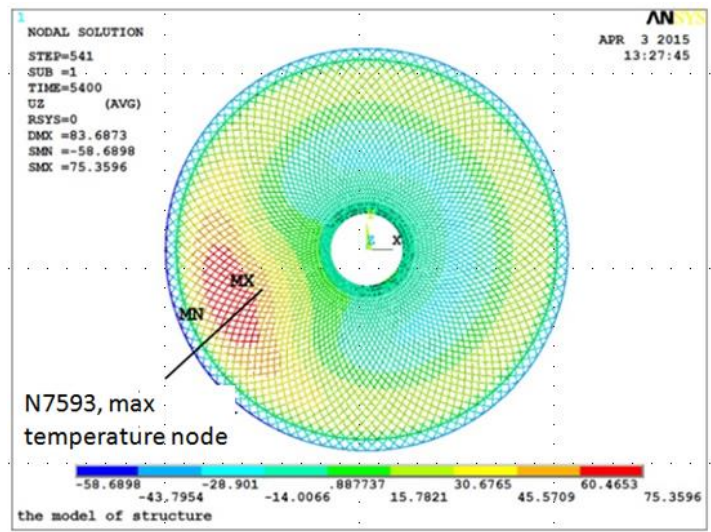

(b) Fire Scenario 2

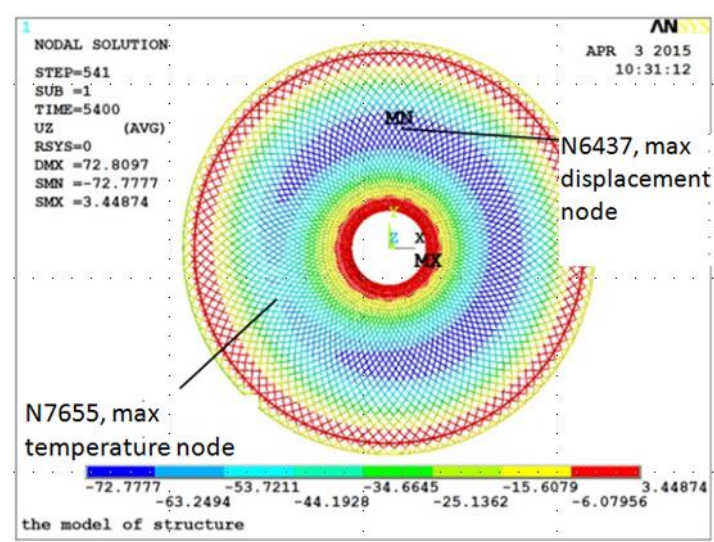

(d) Fire Scenario 4

Fig. 15 The vertical nodal displacement contours in the bottom chord of the steel truss structure for four fire scenarios at $5400 s$ fire time.

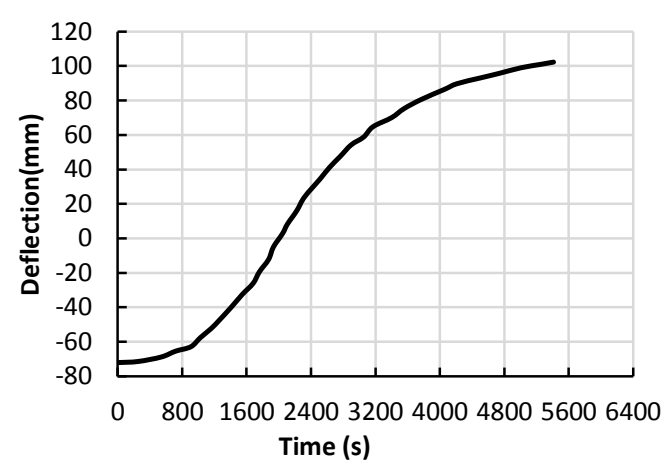

(a) Node N3467

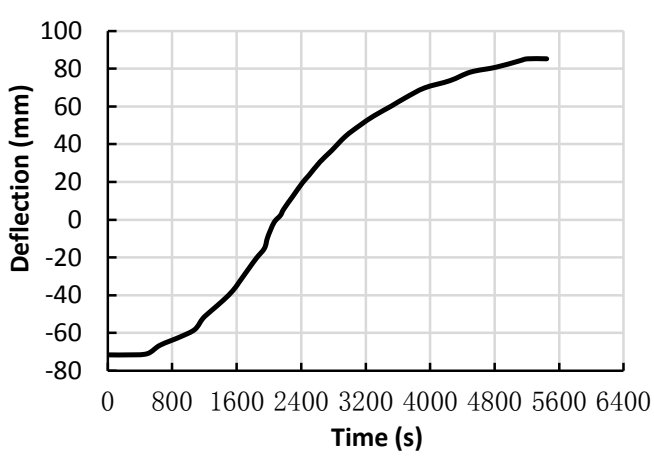

(b) Node N7425

Fig. 16 The vertical displacement-time curves of the nodes N3467 and N7425, which experienced the highest temperatures within the top and bottom chords. 


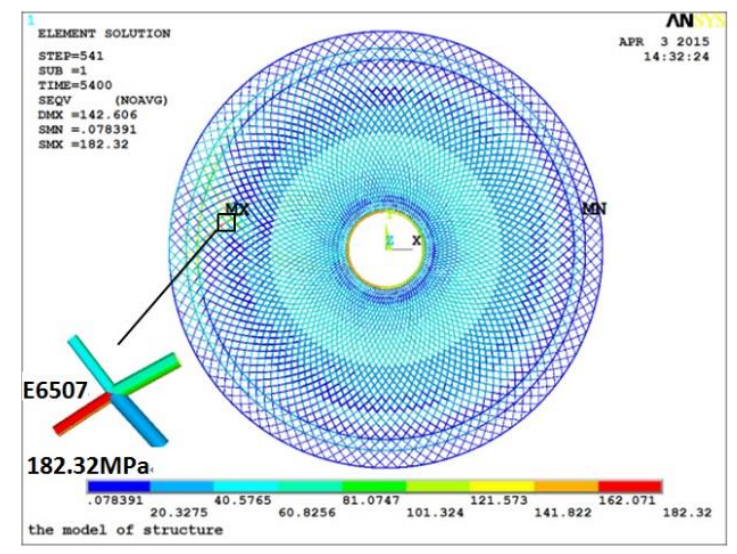

(a) Fire Scenario 1

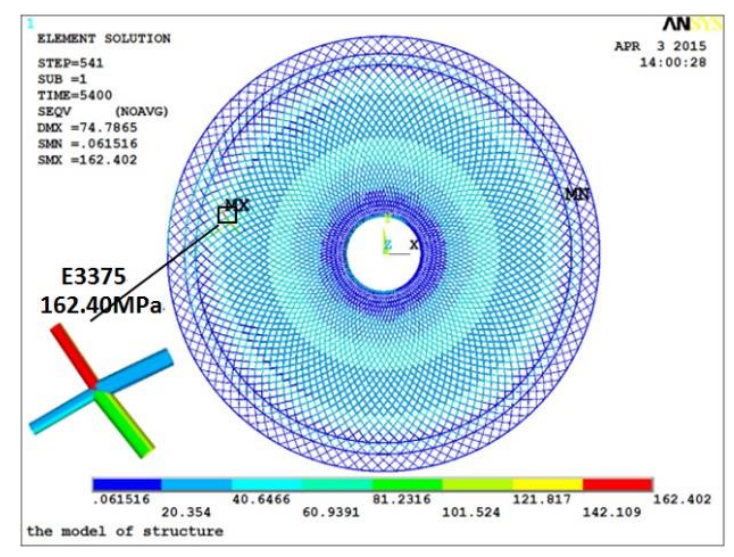

(c) Fire Scenario 3

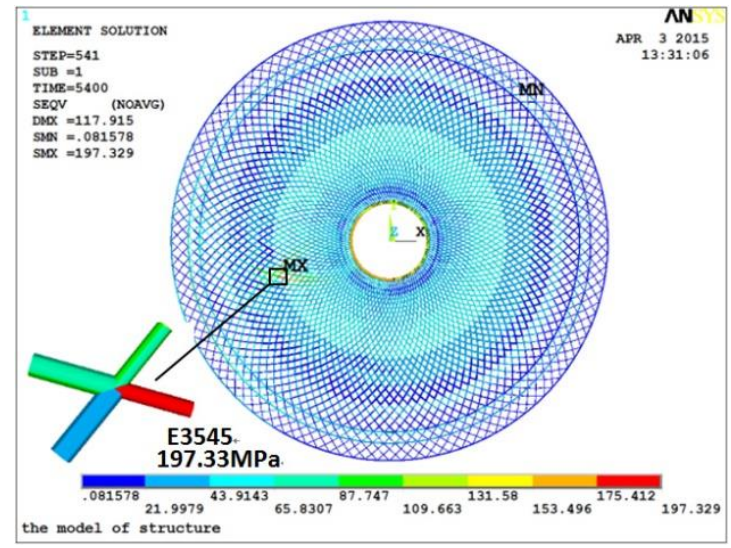

(b) Fire Scenario 2

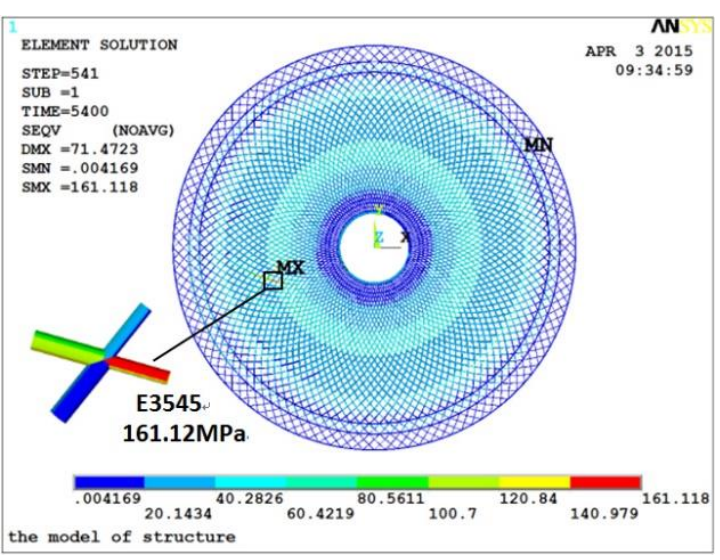

(d) Fire Scenario 4

Fig. 17 The stresses of the members on the top chord of the steel truss structure for four fire scenarios at $5400 s$ fire time. 


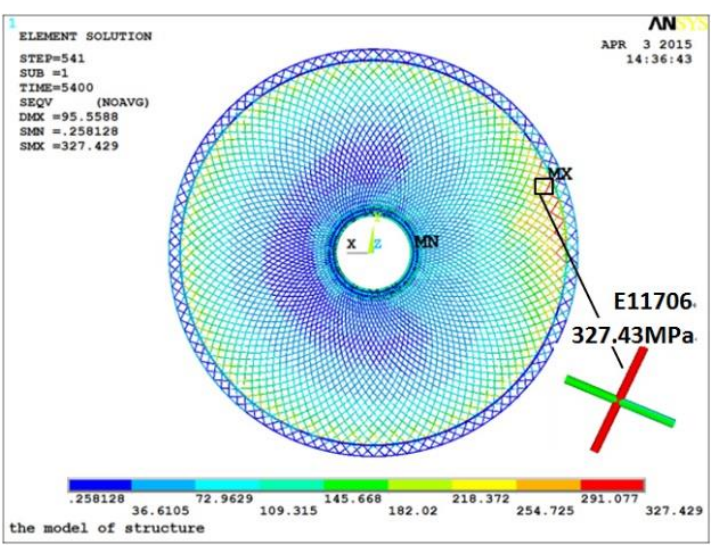

(a) Fire Scenario 1

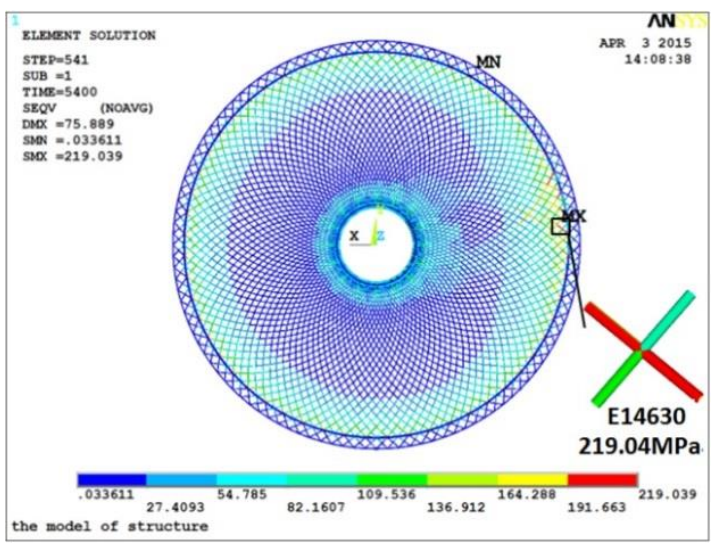

(c) Fire Scenario 3

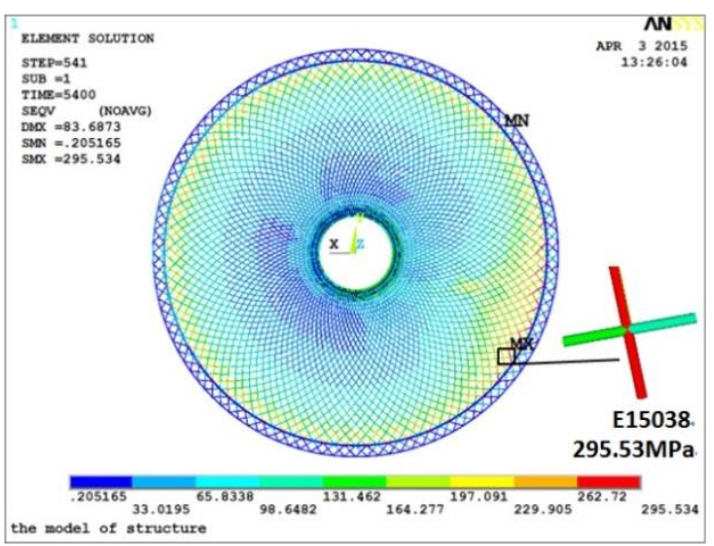

(b) Fire Scenario 2

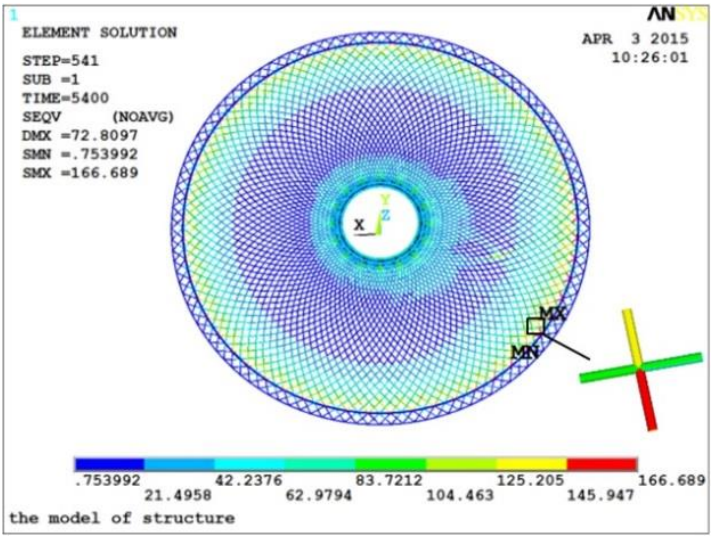

(d) Fire Scenario 4

Fig. 18 The Stresses of the members on the bottom chord of the steel truss structure for four fire scenarios at $5400 s$ fire time.

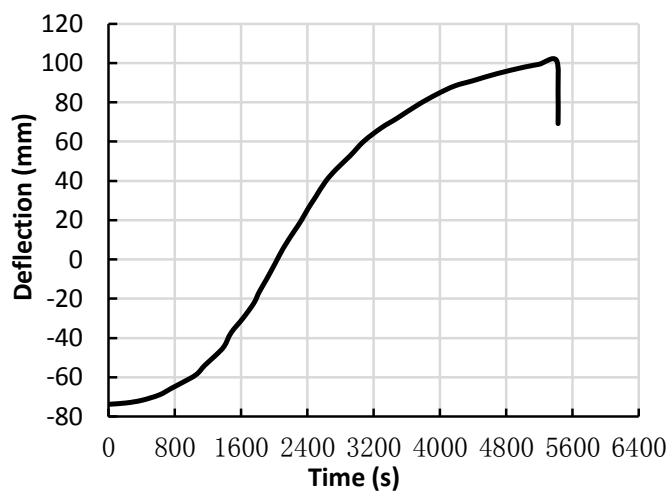

(a) Node N3467

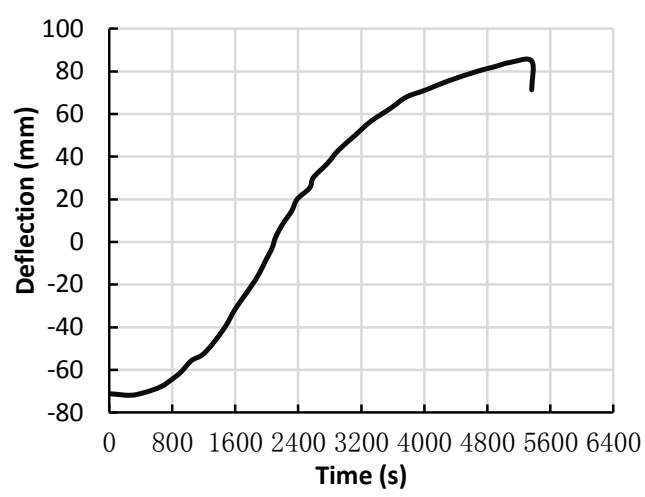

(b) Node N7425

Fig. 19 The vertical displacement-time curves of the nodes N3467 and N7425 within the top and bottom chords after partial cooling. 